\title{
¿Intercambio compensado entre inflación y desempleo? El estado como empleador directo *
}

\section{Trade off between inflation and unemployment? The state as a direct employer}

\author{
Jorge G. Osorio Vaccaro**
}

\section{RESUMEN}

En este documento se planteará, contrariamente a lo que sugiere la ortodoxia predominante en la ciencia económica, que el bienestar de la sociedad mejora no solo con el control de la inflación sino también, y posiblemente más importante, con la reducción del desempleo. Como se verá, los objetivos de reducir el desempleo a través de la intervención estatal directa utilizando políticas de demanda activista, como lo sugiere el enfoque poskeynesiano, no acelerarán la inflación.

En consecuencia, no sería cierto, como lo sugiere el análisis derivado de la curva de Phillips, que reducir el desempleo necesariamente aumentaría la inflación y que para que esto no suceda, se debe establecer una cierta meta de NAIRU (una tasa de desempleo que no acelera la inflación). El enfoque que se presentará, en línea con lo que sugiere la Escuela Poskeynesiana, sostiene que el estado puede asumir el papel de "empleador de mano de obra de último recurso". De esta manera, el estado podría contratar directamente mano de obra desempleada (abiertamente o disfrazada de

(*) El artículo se ha elaborado con la finalidad de estimular el tratamiento pluralista de la ciencia macroeconómica, divulgando enfoques teóricos alternativos como los planteados por la Escuela Poskeynesiana y promover el debate.

(**) Profesor principal e investigador de la Facultad de Ciencias Económicas, Universidad Nacional Mayor de San Marcos. Calle Germán Amézaga 375, Lima, Perú. Economista y Doctor en Economía, Universidad Nacional Mayor de San Marcos, Lima, Perú. Master of Arts in Economics, Vanderbilt University, Nashville, Tenn. USA. Tlf.: 999021135. E-mail: josoriov@unmsm.edu.pe

(C) Los autores. Este artículo es publicado por Pensamiento Crítico de la Facultad de Ciencias Económicas, Universidad Nacional Mayor de San Marcos. Este es un artículo de acceso abierto, distribuido bajo los términos de la licencia Creative Commons Atribucion - No Comercia_Compartir Igual 4.0 Internacional. (http://creativecommons.org/licenses/by-nc-sa/4.0/) que permite el uso no comercial, distribución y reproducción en cualquier medio, siempre que la obra original sea debidamente citada. 
informalidad), la que constituye un grave problema para las economías en desarrollo. Palabras claves: Desempleo; Subempleo; Inflación; Rol del Estado; Bienestar. JEL: J08

\section{ABSTRACT}

In this paper it will be raised, contrary to what is suggested by the predominant orthodoxy in economic science, that the welfare of society improves not only controlling inflation but also and possibly more importantly, reducing unemployment. As will be seen, the objectives of reducing unemployment through direct state intervention using activist demand policies, as suggested by the Post Keynesian approach, would not accelerate inflation. Consequently, it would not be true as suggested by the analysis derived from the Phillips Curve, that reducing unemployment would necessarily increase inflation and that for this to not happen a certain NAIRU goal must be set (an unemployment rate that does not accelerate inflation). The approach that will be presented, in line with what is suggested by the Poskeynesian School, argues that the state can assume the role of "employer of last resort labor". In this way, the state could directly hire unemployed labor (openly or disguised as informality), which constitutes a serious problem for developing economies.

Keywords: Unemployment; Underemployment; Inflation; Role of theState; Welfare. JEL: J08

\section{Introducción}

En las aulas de economía se analiza que, en el corto plazo, la política económica debe centrarse en alcanzar dos objetivos fundamentales para el bienestar de la sociedad: la estabilidad de precios y el pleno empleo.

En por lo menos las tres últimas décadas, los tomadores de decisiones de política económica en casi todos los países, aparentemente han privilegiado únicamente uno de los dos: la estabilización de precios, tratando de alcanzarla a través de una lucha constante contra la inflación. Sin embargo, la búsqueda del pleno empleo se abandonó, por lo menos como política explícita. Es evidente que, en términos de una mejora del bienestar, reducir tanto la inflación como el desempleo (el abierto y el disfrazado por la informalidad) son objetivos que deben perseguirse permanentemente. Pero ¿qué ocurrió con la búsqueda del pleno empleo a un nivel adecuado? ¿Acaso es menos importante para el bienestar que todas las personas tengan un puesto de trabajo satisfactorio que impedir que los precios aumenten continua y sostenidamente? ¿Se pueden lograr ambos objetivos o ellos son antagónicos? 
La razón de haber preferido, en las últimas décadas, estabilizar los precios podríamos encontrarla en la historia del pensamiento económico y en el predominio de una manera de pensar economía sobre formas alternativas de interpretarla.

En el presente trabajo se tratará de plantear, contrariamente a lo sugerido por la ortodoxia predominante en la ciencia económica, que el bienestar de la sociedad mejora no solo controlando la inflación sino también y posiblemente de manera más importante, reduciendo el desempleo. Como se verá, los objetivos de reducir el desempleo mediante la intervención directa del estado via políticas activistas de demanda, tal como lo sugiere el enfoque Poskeynesiano no aceleríanla inflación. En consecuencia, no sería necesariamente cierto como lo sugiere el análisis derivado de la Curva de Phillips, que reducir el desempleo aumentaría necesariamente la inflación y que para que esto no ocurra debe fijarse una cierta meta NAIRU (una tasa de desempleo que no acelere la inflación). El enfoque que se presentará, en línea con lo sugerido por la escuela Poskeynesiana, argumenta que el estado puede asumir el rol de "empleador de mano de obra de último recurso". ${ }^{1}$ En esta forma el estado podría contratar directamente la mano de obra desempleada (abiertamente o disfrazada de informalidad) que constituye un grave problema para las economías en desarrollo.

En la primera parte se presentará el trade off entre empleo e inflación que plantea la Curva dePhillips, con el objeto de revisar el antagonismo existente entre la fijación de metas de inflación y de desempleo, así como la introducción de expectativas adaptativas y racionales con el fin de ilustrar la inevitabilidad de la tasa natural de desempleo como la única que no acelera la inflación (la NAIRU), lo que probablemente ha conducido a enfatizar el control de la inflación sobre otros objetivos. En la Parte II, luego de un breve recuento de algunas medidas ortodoxas para corregir las rigideces estruturales del mercado de trabajo; se plantea la cuestión de si es posible reducir el desempleo utilizando políticas activistas de demanda sin que necesariamente se acelere la inflación. Para ello se evalúan las fundamentales diferencias entre el análisis del mercado de trabajo de la ortodoxia Neoclásica y el planteado por el Poskeynesianismo que establece una relación directa entre los salarios reales y el nivel de empleo de la mano de obra, que haría innecesaria la fijación de la NAIRU e identifica una situación de "pleno empleo" con un significativo "bolsón" de 
desempleo "disfrazado" (subempleo o empleo informal). En la Parte III se evalúa la propuesta Poskeynesiana de usar al estado como "empleador de última instancia” para absorber directamente el desempleo, particularmente el subempleo, en la marcha al logro de un pleno empleo similar al de los países avanzados sin que, en general, se deba acelerar la inflación. En la Parte IV se reseña brevemente algunas investigaciones que determinarían que el esfuerzo por reducir el desempleo., que no es un objetivo directo de las políticas actuales, aumentaría más el bienestar que el control de la inflación. Finalmente, en la conclusión se enfatiza la necesidad de dar el mismo o mayor énfasis a políticas económicas orientadas a reducir el desempleo, especialmente de aquel disfrazado en la informalidad, con el fin de mejorar el bienestar de la sociedad.

\section{La curva de Phillips y el "trade-off” entre inflacion y desempleo}

En sus "Notas Finales sobre la Filosofía Social a que podría conducir la Teoría General", contenidas en el Capítulo 24 de la "Teoría General sobre la Ocupación, el Interés y el Dinero" (Traducción de Eduardo Hornedo. Revisión de Angel Martín Pérez. Fondo de Cultura Económica. Séptima Edición en Español, 1965), uno de los libros más importantes que se han escrito sobre economía, John M. Keynes escribió: "Los principales inconvenientes de la sociedad económica en la que vivimos son su incapacidad para procurar la ocupación plena y su arbitraria y desigual distribución de la riqueza y los ingresos". (op. cit., p. 328).

En el Capítulo 23 de la Teoría General (op. cit., p. 320), Keynes cita a Bernard de Mandeville, filósofo del Siglo XVII que se opusiera siempre las "frívolas regulaciones de la prodigalidad y la frugalidad" para buscar la felicidad de las naciones y que basaba en el empleo la grandeza de las naciones. Keynes, cita a Mandeville concluyendo:

El gran arte para hacer que una nación sea feliz y lo que llamamos floreciente, consiste en dar a todos y cada uno la oportunidad de estar empleado; y para obtenerlo, hágase que la primera preocupación del gobierno sea promover una variedad tan grande de manufacturas, artes y oficios como la inteligencia humana pueda inventar; y la segunda, estimular la agricultura y la pesca en todas sus ramas, que se obligue a toda la tierra a esforzarse lo mismo que el hombre.

Como es ampliamente conocido la revolución que Keynes y sus seguidores del "Circus"de Cambridge al presentar a la demanda efectiva 
como la fuerza que mueve la economía, en la práctica elimina la idea que toda oferta genera su propia demanda establecida por la denominada Ley de Say y rechaza la posibilidad de un equilibrio general con pleno empleo automático de los factores de producción. Un aporte, en nuestra opinión, fundamental de Keynes y del Circus es que, a diferencia de una conceptualización del tiempo como "tiempo lógico" que él atribuía a los Clásicos ${ }^{2}$, plantea el concepto de "tiempo histórico" (tiempo real). Es debido a la existencia del tiempo histórico; esto es, a que el proceso de producción toma tiempo y al hecho que los que planean y llevan a cabo la producción no son, en general, los mismos que la van a comprar cuando esta producción esté disponible (luego de transcurrir un tiempo) es sumamente improbable ${ }^{3}$ que la compra efectiva de bienes y servicios al final del periodo de producción sea igual a la que se programó producir y vender. Si la demanda efectiva es inferior a la oferta, la consecuencia es el desempleoy, como ocurrió en la Gran Depresión de 1929, la "Mano Invisible", la "Eficiencia de los Mercados" fue incapaz de eliminar el agudo desempleo que ocurriera en esa época.

La solución se logró mediante la intervención directa del estado: "La Mano Visible", utilizando apropiadamente la política económica. ${ }^{4}$ Como sabemos, la propuesta de Keynes era sencilla. Frente a la grave insuficiencia de demanda efectiva ocurrida durante la Gran Depresión, la solución radicaba en estimularla directamente. El asunto está en que no había forma práctica de aumentar el consumo ya que el agudo desempleo redujo este tipo de gasto $y$, en tales circunstancias esperar que un inversionista aumente sus gastos en nuevo capital resultaba bastante irreal; por consiguiente, resultaba obvio que correspondiera al estado intervenir directamente para estimular la demanda aumentando el gasto público. Esta solución, que propone la intervención directa del estado nunca, hasta hoy, ha sido bien recibida por los que veían a esta intervención como peligrosa para el libre mercado en la solución de los problemas económicos. Creemos que los economistas se ha polarizado desde entonces entre los que abogan por una intervención del estado que corrija las fallas del mercado y los que defienden la "eficiencia de los mercados" 5 como suficiente, haciendo innecesaria cualquier tipo de intervención gubernamental directa.

Un Keynesianismo "intervencionista” debía ser combatido por los creyentes en la eficiencia de los mercados. Una importante oposición al 
"intervencionismo" la planteó Harry G. Johnson. ${ }^{6}$ Alaba a Keynes y pondera el significativo efecto que su revolución tuvo para superar la Gran Depresión y combatir el desempleo; sin embargo considera que las economías, al haber alcanzado el pleno empleo, no necesitan del Keynesianismo para resolver los nuevos retos, como la inflación, pues su enfoque no contempla este problema. En consecuencia, es necesario buscar teoríasy políticas económicas que ayuden a encontrar las soluciones adecuadas. Según Johnson, no era necesario buscar mucho pues la teoría Neoclásica (la teoría Neoclásica del Ajuste de Precios) analiza el problema de la variación de los precios y sugiere correctivos apropiados. Los teóricos, en particular la mayoría "No intervencionista" aplaudió este regreso a la ortodoxia pre-Keynesiana. ${ }^{7}$ El énfasis cambia radicalmente del uso de políticas para combatir el desempleo, ahora supuestamente innecesarias, a políticas destinadas a combatir la inflación. Este sesgo, dentro de la ortodoxia vigente, no ha cambiado significativamente hasta hoy.

Muchos de los defensores de las ideas de Keynes manifestaron su abierta oposición al planteamiento Neo-neoclásico, desde mucho antes de lo expresado por Johnson en 1961, afirmando que el enfoque Keynesianono se limitaba a tratar el problema del desempleo sino al análisis de los fenómenos inherentes al ciclo económico, entre ellos el problema de la inflación. El abanderado de esta posición es Paul A. Samuelson. ${ }^{8}$ En su enfoque denominado "La Síntesis Neoclásica/Neokeynesiana", aunque conocida generalmente como la "Síntesis Neoclásica" junta tres enfoques que históricamente se desarrollaron por separado: a) El enfoque de la Oferta Agregada Neoclásica (Pre Keynesiana); b) el Enfoque de la Demanda Agregada Keynesiana (a la Hicks/Samuelson); y c) El Enfoque del Ajuste de Precios a partir de la Curva de Phillips.

Muchos autores, entre ellos Jorge Segura (en Estratega Financiero: "La Aparición de los Nuevos Clásicos y Neo-Keynesianos" (p. 20), tomado de https://estrategafinanciero.com/la-aparicion-de-los-nuevos-clasicos-yneo-keynesianos/), citan las declaraciones de Samuelson en 1955:

En años recientes, el 90 por ciento de los economistas americanos han dejado de ser keynesianos o no keynesianos. En vez de ello, han trabajado hacia una síntesis de aquello que sea valioso en la teoría económica más antigua y en las teorías modernas de la determinación del ingreso. Este resultado puede ser llamado economía neoclásica y es aceptado, en sus visión general, por todos excepto por el cinco por ciento de escritores del ala de extrema izquierda y de extrema derecha. 
La propuesta de la Síntesis Neoclásica gozó de gran aceptación. ${ }^{10}$ Esta síntesis aceptaba, siguiendo el planteamiento de la Teoría Neoclásica tradicional, la existencia de pleno empleo de los factores de producción y la rigidez de la oferta agregada a nivel del pleno empleo. Aceptaba también la proposición de una demanda agregada típicamente Keynesiana derivada de las conocidas funciones IS y LM. Junto a una oferta y demanda agregadas, esencialmente estáticas, se agrega un mecanismo de ajuste dinámico de los precios y de la tasa de desempleo que se explicita en la mencionada Curva de Phillips. ${ }^{11}$

Es importante detenerse a analizar la Curva Phillips: En su planteamiento original, Phillips estableció la existencia de una relación negativa entre la tasa de crecimiento de los salarios nominales y el exceso de oferta en el mercado laboral (desempleo), en el Reino Unido. Basándose en este hallazgo, Paul A. Samuelson y Robert Solow, del MIT, en su artículo "AnalyticalAspects of Anti-InflationPolicy," American EconomicReview 50 (Mayo, 1960), pp. 177-194, proponen una "ampliación" del análisis de Phillips, encontrando una relación negativa, a corto plazo, entre la tasa de inflación y la tasa de desempleo lo que ofreció una justificación econométrica a la forma como Samuelson concebía la teoría Keynesiana, en el sentido que, como ya se mencionó, el análisis del desempleo no era independiente del análisis de la inflación Desde los años 1960s esta relación se conoce como la Curva de Phillips. ${ }^{12}$

Una presentación usual de la Curva de Phillips es: $\boldsymbol{\pi}=-\boldsymbol{\alpha}(\mathbf{u})$; donde $\pi$ representa la tasa de inflación; $\boldsymbol{\alpha}$ es un parámetro y $\mathbf{u}$ es la tasa de desempleo, generalmente definida como la diferencia entre $\left(\mathbf{N} / \mathbf{N}^{*} \mathbf{- 1}\right)$, donde $\mathbf{N}$ es la cantidad de mano de obra empleada y $\mathbf{N}^{*}$ es la Población Económicamente Activa, de manera que $\mathbf{N}=\mathbf{N}^{*}$ implicaría el pleno empleo de la mano de obra.

La Curva de Phillips representaba bastante bien lo que ocurrió en la década delos 1960s en los EE.UU.Como puede observarse, pone de manifiesto que existe un "intercambio compensado" (unTrade-off) entre el desempleo y la inflación. ${ }^{13}$ Este intercambio implica fundamentalmente que las políticas gubernamentales (la "Mano Visible") resultan importantes para regular la marcha de la economía. Bajo esta concepción, el gobierno podía establecer, si la presión social era fuerte, una meta de reduc- 
ción del desempleo y orientar la política económica para lograrla, pero sabiendo que debía"pagarla" con mayor inflación. Alternativamente si la economía se "calentaba" demasiado era posible actuar para reducir la inflación aunque al costo de un mayor desempleo. Se estableció así lo que se denominara una "Política de Afinamiento", o de "Puesta a Punto" ("Fine TuningPolicy"). Es importante reiterar aquí que esta política justificaba la intervención del gobierno.

Sin embargo, una defensa de la "no intervención"y de la "soberanía del mercado" no se hizo esperar. Primero Edmund Phelps (Columbia University, 1967) y luego Milton Friedman (University of Chicago, 1968), cuestionaron la estabilidad de la curva de Phillips en el largo plazo. La tasa de inflación $(\pi)$, que en la curva se asumía como representando el cambio continuo y sostenido en el nivel general de preciosno tenía sentido toda vez que el análisis de Phillips se desprende de la curva de ajuste de precios formulada por la teoría Neoclásica, la misma que necesariamente se refiere a valores relativos y no absolutos. En consecuencia, una correcta interpretación de la Curva de Phillips implica necesariamente tener en cuenta cambios relativos en el nivel general de precios. La solución aceptada por todos los autores es considerar que la relación de Phillips en realidad representa cambios en los precios en los precios observados en relación con los cambios que los agentes económicos esperan que ocurran en el nivel general de precios. Esto introduce un elemento crucial en el análisis económico: Las expectativas. Su consideración establece una diferencia entre la conceptualización de la Curva de Phillipsa corto plazo, aquella que aunque la tasa de inflación de mercado varíe, no se altera la tasa de inflación esperada (se mantiene la relación inversa entre la tasa de inflación y la de desempleo) y la de largo plazo, donde la tasa de inflación observada es la misma que la esperada (La curva se vuelve vertical). A corto plazo funciona con éxito la intervención gubernamental: se reduce el desempleo aunque a costa de aumentar la inflación. A largo plazo la intervención no genera reducciones en la tasa de desempleo aunque "dispara" la inflación.

La introducción de las expectativas, en la forma propuesta por Friedman y Phelps elimina, por lo menos en el largo plazo, la necesidad de la intervención gubernamental en la economía, pues esta intervención lo único que genera es una inflación sostenida sin cambio en las variables 
reales (en particular, sin reducir el desempleo). Esta eliminación de la intervención de la "mano visible" obedece a una formulación que comienza considerando que como la tasa de desempleo tiene sentido medirla como la diferencia entre la tasa de desempleo observada (u) y la denominada tasa natural de desempleo ( $\mathbf{u}^{*}$ ), que es aquella que ocurre cuando la tasa de inflación es igual a cero o, alternativamente, cuando hay equilibrio general en la economía. Generalmente se asume que $\mathbf{u}^{*}$ prevalece cuando hay "pleno empleo", pues se reconoce que no es posible alcanzar el pleno empleo absoluto.

Así, la versión presentada antes de la curva de Phillips se modifica por otra que incluye tanto la tasa esperada de inflación $\left(\pi^{\mathrm{e}}\right)$ como la tasa natural de desempleo ( $\left.\mathbf{u}^{*}\right)$; esto es: $\boldsymbol{\pi}=\pi^{\mathrm{e}}-\boldsymbol{\alpha}\left(\mathbf{u}-\mathbf{u}^{*}\right) \cdot{ }^{14}$ A partir de esta formulación es posible explicar la diferencia entre las curvas de corto y largo plazo. Si inicialmente la tasa de inflación real (observada) fuera cero y los agentes la toman para fijar sus expectativas, ello sería consistente con una situación en la queu $=\mathbf{u}^{*}$ (la tasa de desempleo observada es igual a su tasa natural; esto es, aquella que se observaría cuando el PBI está en su potencial). Si resultara por ejemplo que $\mathbf{u}^{*}$ fuera muy alta, una política monetaria activista podría estimular la demanda agregada y reducir la tasa de inflación estableciendo una diferencia ( $\left.\mathbf{u}-\mathbf{u}^{*}\right)$ negativa lo que, sin cambios en las expectativas, aumentaría la tasa de inflación observada.

Por ejemplo, si $\mathbf{\pi}^{\mathrm{e}}=\mathbf{0} ; \boldsymbol{\alpha}=\mathbf{0 . 5} ; \mathbf{u}=\mathbf{4 \%} \mathbf{y} \mathbf{u}^{*}=\mathbf{8} \%$, entonces $\boldsymbol{\pi}$ debería ser igual a $\mathbf{2 \%}$. En otras palabras, si inicialmente la economía experimentara una situación en la que $\pi=\pi^{\mathrm{e}}=\mathbf{0}$ y $\mathbf{u}=\mathbf{u}^{*}=\mathbf{8} \%$; $\mathrm{y}$ el gobierno decide reducir la tasa de inflación en $\mathbf{4 \%}$ (hacer $\mathbf{u}=\mathbf{4 \%}$ ), tendría que aceptar un aumento en la tasa de inflación de $\mathbf{2 \%}$. En este caso, se verificaría que la intervención (la "mano visible") resulta exitosa en reducir el desempleo a costa de un incremento en la inflación. Sin embargo, para que esto ocurra los agentes económicos no deberían cambiar sus expectativas acerca de la inflación; esto es, mantener $\boldsymbol{\pi}^{\mathrm{e}}=\mathbf{0}$ a pesar que $\boldsymbol{\pi}$ es ahora igual a $\mathbf{2 \%}$. Esta situación se daría si el gobierno no anuncia la intervención con la debida anticipación, induciendo a los agentes a cometer errores de estimación.

Pero debido a que los errores de estimación son costosos, los agentes tenderían a corregirlos de manera que, en el tiempo, u volvería a su nivel natural (a $\mathbf{u}^{*}$, a 8\%), anulando lo logrado con la intervención. En el plant- 
eamiento de Friedman y Phelps, esta corrección ocurre en el largo plazo lo que implicaría que la inflación resultaría independiente de la tasa de desempleo, en virtud de lo que ellos denominaron expectativas adaptativas. Así, en el largo plazo los agentes incorporarían en sus expectativas la tasa más alta de inflación generada por la intervención con el resultado que el desempleo, en el ejemplo planteado, volvería a su nivel inicial de $\mathbf{8 \%}$ pero la inflación se mantendría en $\mathbf{2 \%}$ (no regresaría a cero): $\mathbf{2 \%}=$ $2 \%-0.5(8 \%-8 \%)$.

En estas circunstancias, si el gobierno desea mantener el desempleo en 4\% tendría que "pagar" con tasas de inflación crecientes, lo que destruiría el Trade-off entre desempleo e inflación. Así, en el largo plazo la curva de Phillips se volvería completamente vertical e indicaría que la inflación crecería continuamente sin que el desempleo se mueva de $\mathbf{4 \%}$ a pesar de que el gobierno mantenga continuamente, una política económica activista que alimentaría sostenidamente la inflación. Esta situación se puede apreciar en el gráfico 1.

1. Inicialmente la economía se ubica en $\mathbf{u}=\mathbf{u}^{*}=\mathbf{8} \%$ y $\boldsymbol{\pi}=\boldsymbol{\pi}^{\mathrm{e}}=\mathbf{0}$. Por $\mathbf{u}^{*}$ (8\% en el gráfico) pasa la curva de Phillips $\mathbf{C P}_{\mathbf{1}}$. Esta es una curva considerada como de corto plazo, que refleja, a todo lo largo de ella que $\boldsymbol{\pi}^{\mathrm{e}}=\mathbf{0}$.

2. Una política monetaria activista logra reducir la tasa de desempleo de $\mathbf{8 \%}$ a $\mathbf{4 \%}$ y la economía se ubica sobre $\mathbf{C P}_{\mathbf{1}}$ enA, apreciándose que esta reducción eleva la tasa de inflación a $\mathbf{2 \%}$. En el corto plazo, si los agentes económicos no cambian sus expectativas (continúan sobre $\mathbf{C P}_{1}$ ) la intervención resulta exitosa al reducir u de $\mathbf{8 \%}$ a $\mathbf{4 \%}$, aunque el costo sea un alza en $\pi$ de $\mathbf{0}$ a $\mathbf{2 \%}$.

3. En virtud de las expectativas adaptativas los agentes empiezan a corregir las diferencias entre la tasa de inflación que observan y la que deben esperar, introduciendo progresivamente en esta última la tasa observada. Este proceso ocurre en el largo plazo. Gráficamente, lo que ocurre es un desplazamiento de $\mathbf{C P}_{1}$ a otra curva de corto plazo que, en toda su extensión, deje constante la nueva tasa de inflación esperada (aquí sería una nueva curva $\mathbf{C P}^{\prime}{ }_{1}$ paralela a $\mathbf{C P}_{\mathbf{1}}$ no considerada en el gráfico, que pasaría por $\mathbf{B}$ : por $\left(\mathbf{u}=\mathbf{u}^{*}=\right.$ $8 \%$ con $\pi=\left(\pi^{\mathrm{e}}=2 \%\right)$, anulándose la reducción en el desempleo. 
4. Si el gobierno quiere volver a establecer una tasa de desempleo de $\mathbf{4 \%}$, menor que la tasa natural, la economía se ubicaría sobre $\mathbf{C P}^{\prime}{ }_{\mathbf{1}}$ (que también contiene a $\mathbf{B}$ ) en el punto $\mathbf{C}$ (exactamente encima de $\mathbf{A}$ ). En el punto $\mathbf{C}$ se observa que mantener la tasa de desempleo en $\mathbf{4 \%}$ se "pagaría" con una tasa de inflación también de $\mathbf{4 \%}$. Nuevamente, en el largo plazo, la $\mathbf{C P}_{1}$ se desplazaría a $\mathbf{C P}_{2}$ que como se aprecia pasa por $D$, donde $\left(\mathbf{u}=\mathbf{u}^{*}=\mathbf{8} \%\right.$ con $\pi=\pi^{\mathbf{e}}=\mathbf{4 \%}$ ), anulándose nuevamente la reducción del desempleo.

5. Una nueva intervención para reducir el desempleo hasta el 4\%conduciría al sistema hasta $\mathbf{C P}_{3}$ ubicándose en el punto $\mathbf{F}$, donde se tendría $\left(\mathbf{u}=\mathbf{u}^{*}=8 \%\right.$ con $\left.\pi=\pi^{\mathrm{e}}=\mathbf{6 \%}\right)$ y así sucesivamente.

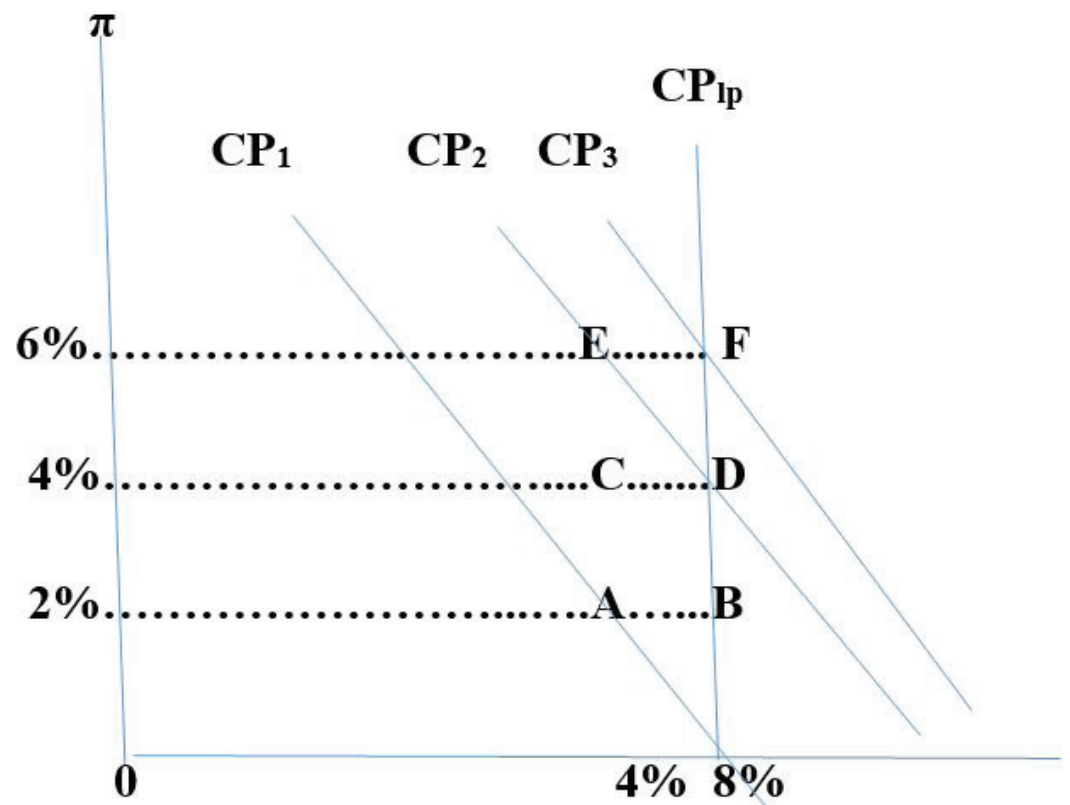

Gráfico 1. Representacion gráfica de la curva de phillips a corto y largo plazo

Como se aprecia, a corto plazo, opera el Trade-off entre desempleo e inflación y justifica la intervención (la "Mano Visible") del gobierno. Sin embargo, a largo plazo, la intervención no reduciría el desempleo y 
aceleraría la inflación. El planteo de Friedman y Phelps explicaría razonablemente bien lo que, a principios de los 1970s, se observó en los EE.UU. A diferencia de la década anterior en la que se apreció una relación inversa básicamente estable entre $\pi$ y u. En 1970-1972 en diferentes países se notó que ambas tasas se relacionaban directamente, aumentando al mismo tiempo ("estanflación"), lo que analíticamente se explicaría por el desplazamiento a la derecha de las curvas de Phillips de corto plazo, tal como se señaló antes.

Lo importante para nosotros hasta aquí es que la crítica a la curva de Phillips justificaría el rechazo a la intervención del gobierno y una defensa del papel de la "Mano Invisible".

En verdad, la Hipótesis de Expectativas Adaptativas, que son la base de la crítica de Friedman y Phelps, fue presentada inicialmente por Cagan (1956), quien planteó que las expectativas de los agentes económicos se forman a partir de analizar cómo se portan las variables que resultan importantes para formular tales expectativas. Es evidente que los agentes cometerán errores en el proceso. Si estos errores son sistemáticos ello dará lugar, en el corto plazo, a desequilibrios que, como se mencionó antes, permiten al gobierno reducir el desempleo. Sin embargo, como los errores generan costos, los agentes aprenderán a corregirlos ("expectativas adaptativas”), garantizándose la tendencia a un equilibrio en el largo plazo.

Pero una expectativa adaptativa reflejaría una forma de irracionalidad de comportamiento por parte de los agentes, ya que implicaría que los errores (que son siempre costosos) se corregirían parcial y progresivamente a lo largo del tiempo. Lo obvio es que los errores se deben corregir inmediatamente y evitar cometerlos en el futuro inmediato y mediato.

El hecho que no resulta racional admitir un comportamiento que acepte errores sistemáticos, condujo al rechazo de la hipótesis de expectativas adaptativas y a su sustitución por la Hipótesis de Expectativas Racionales (HER), que si bien acepta que errar es humano, rechaza la posibilidad que estos errores sean sistemáticos. Como se verá, anula, aun a corto plazo, la utilidad de la intervención del gobierno para reducir el desempleo y centra la atención, en particular de la política monetaria, en la estabilización; vale decir, en controlar la inflación. 
Como es ampliamente conocido, Robert Lucas Jr. en 1971 introduce la HER, con lo que anula la efectividad de toda intervención que afecte la demanda agregada, pues el activismo estatal conduciría, aún en el corto plazo, a una aceleración de la inflación sin reducir el desempleo. Esto es, se regresa casi completamente al Neoclasicismo del equilibrio general con el desempleo en su tasa natural.

La HER se sostiene fundamentalmente en dos proposiciones; la primera, se basa en el argumento que los agentes económicos, si bien pueden cometer errores individuales, no lo hacen de manera sistemática pues actúan racionalmente evitando repetir cualquier error pues ello es costoso. La HER postula que las expectativas sobre eventos futuros no son sistemáticamente erróneas y en todo caso los errores de estimación resultan aleatorios. La segunda, siguiendo lo propuesto por John Muth en 1961, afirma que un sujeto tiene expectativa racional si su predicción sobre un evento futuro (su expectativa "subjetiva") coincide con la predicción de los expertos, que se asume que disponen de prácticamente toda la información necesaria para dicha predicción (información "perfecta") y la utilizan de manera eficiente. Así, bajo la HER se puede anticipar correctamente cualquier medida de política económica. ${ }^{15}$

En conclusión, si un agente económico se comporta bajo la HER, puede formar expectativas que pueden ser individualmente erradas, pero que resultarían correctas en promedio. De manera que aunque no se pueda tener perfecta certidumbre acerca del futuro, las predicciones de los agentes no resultarían sesgadas sistemáticamente. Esto es, no ocurrirían desviaciones sistemáticas entre el valor que una variable económica tome realmente en el futuro y el valor que los agentes racionales esperan que tome.

Bajo el imperio de la HER, resultaría que la intervención estatal (la "Mano Visible") no podría, ni aún en el corto plazo, reducir la tasa de desempleo debajo de la tasa natural, aunque generaría una aceleración, obviamente indeseada, en la inflación. En conclusión, las políticas activistas de demanda no solo no funcionan sino perjudican pues aceleran la inflación. Una forma gráfica sencilla de ver lo expuesto se presenta a continuación en el gráfico 2 . 


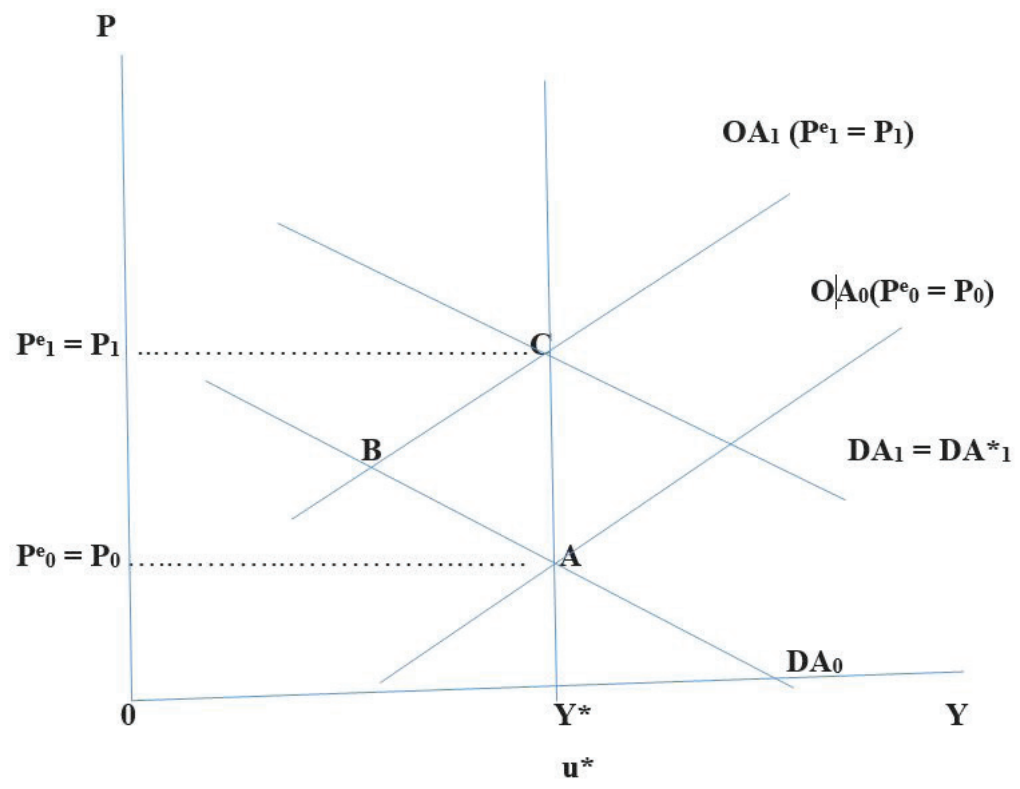

Gráfico 2. Equilibrio general con expectativas racionales

1. $\quad$ P es el nivel de precios: $\mathbf{Y}$ es el PBI; $\mathbf{Y}^{*}$ es el PBI potencial; $\mathbf{u}^{*}$ es la tasa natural de desempleo; $\mathbf{P}^{\mathbf{e}}$ es el nivel esperado de precios; $\mathbf{O A}$ es la oferta agregada ajustada por expectativas; DA es la demanda agregada y $\mathbf{D A}^{\mathrm{e}}$ es la demanda agregada esperada.

2. Partiendo, como es usual, de una situación de equilibrio (Punto A) con el Ingreso Potencial $\left(\mathbf{Y}^{*}\right)$ y la tasa natural de desempleo $\left(\mathbf{u}^{*}\right)$, medidos en el eje de las abscisas y el nivel de precios inicial $\left(\mathbf{P}_{\mathbf{0}}\right)$ en el eje de ordenadas, ocurre que los agentes económicos con expectativas racionales esperaron, en el pasado, que el nivel de precios fuera el que realmente ocurre hoy; esto es, $\left(\mathbf{P}_{\mathbf{0}}=\mathbf{P}_{0}^{\mathbf{e}}\right)$, ello significa que la oferta agregada que incluye expectativas $\mathbf{O} \mathbf{A}_{\mathbf{0}}\left(\mathbf{P}_{\mathbf{0}}^{\mathbf{e}}=\mathbf{P}_{\mathbf{0}}\right)$ se ha construido bajo la consideración, en el momento inicial, que las expectativas acerca de los precios $\left(\mathbf{P}_{0}^{\mathbf{e}}\right)$ coinciden con los precios realmente observados $\left(\mathbf{P}_{\mathbf{0}}\right)$ y debe pasar por $\mathbf{A}$ coincidiendo en dicho punto con la Demanda Agregada (DA $_{0}$ ); en consecuencia, la producción y los precios inicialmente esperados son los que realmente ocurren en el equilibrio inicial. 
3. Estando la economía en A, el gobierno ejecuta una política activista sobre la demanda agregada, ello la desplazaría de $\mathbf{D A}_{\mathbf{0}}$ hasta $\mathbf{D A}_{\mathbf{1}}$. Si los agentes no hubieran previsto esta acción gubernamental (cometiendo un error de estimación), o esta medida no hubiera sido previamente anunciada y contara con la debida credibilidad, entonces la nueva situación de equilibrio general se ubicaría en el punto $\mathbf{B}$, con un nivel de precios, por ejemplo de $\mathbf{P}_{0}{ }_{0}$ (no mostrado en el gráfico) tal que $\mathbf{P}_{\mathbf{1}}>\mathbf{P}_{\mathbf{}_{\mathbf{0}}} \mathbf{}$ $\mathbf{P}_{0}$ y una producción, por ejemplo de $\mathbf{Y}^{\prime}$ (no se muestra), a la derecha de Y*. Así, la política económica hubiera tenido éxito de aumentar la producción y reducir el desempleo, aunque a costa de un alza en el nivel de precios, de $\mathbf{P}_{\mathbf{0}}$ a $\mathbf{P}_{\mathbf{0}}^{\prime}$.

4. Sin embargo, los agentes económicos, que disponen de información perfecta y actúan bajo la HER, pronosticarán correctamente la política económica activista que realizará el gobierno. Como ya se señaló, la acción de política desplazará la $\mathbf{D A}$ de $\mathbf{D A}_{\mathbf{0}}$ a $\mathbf{D} \mathbf{A}_{1}$, pero como hay previsión perfecta, los agentes estimarán correctamente el desplazamiento de la demanda agregada, de manera que $\mathbf{D A}_{\mathbf{1}}=$ $\mathbf{D A}^{\mathrm{e}}{ }_{1}$. Además, la previsión del desplazamiento de la demanda implica que los agentes esperen también que los precios se incrementen, por lo que revisarán y corregirán sus expectativas de precios hacia arriba, esperando que estos aumenten hasta $\mathbf{P}_{1}^{\mathbf{e}}$, que es exactamente hasta donde los precios aumentarán verdaderamente. Este cambio de expectativas hará que la oferta agregada se desplace desde $\mathbf{O A} \mathbf{A}_{0}\left(\mathbf{P}_{0}=\mathbf{P}_{0}^{\mathrm{e}}\right)$ hasta $\mathbf{O A} \mathbf{A}_{\mathbf{1}}\left(\mathbf{P}_{\mathbf{1}}=\mathbf{P} \mathbf{e}_{\mathbf{1}}\right)$ y cruce a la nueva demanda agregada en el punto $\mathbf{C}$.

5. El resultado final, en el punto $\mathbf{C}$, tiene importantes connotaciones. Bajo la previsión que implica la aplicación de la HER la política activista, pronosticada correctamente por los agentes económicos, anula los efectos positivos de esta política, ya que el incremento en la producción y la consiguiente reducción en la tasa de desempleo, que se muestran en el punto $\mathbf{B}$, desaparecerían si los agentes tienen expectativas racionales y se volvería a la situación inicial $\left(\mathbf{Y}^{*}, \mathbf{u}^{*}\right)$, aunque con una, obviamente indeseable, alza en el nivel de precios.

6. Se reitera la gran conclusión: las políticas activistas de demanda no solo no logran los objetivos que se esperan sino que actúan agravan- 
do un mal, la inflación. De manera que, en las últimas décadas prácticamente la única meta de la política económica, especialmente la monetaria, bajo la ortodoxia vigente, es la estabilidad de los precios ya que no es posible hacer nada para reducir el desempleo más allá de la tasa natural.

\section{II. ¿Realmente no es posible hacer nada para reducir el desempleo?}

Entonces, según lo expuesto resulta imposible una solución que no contemple la tasa natural de desempleo (la NAIRU) como la única coherente con una tasa de inflación estable y con una situación de equilibrio general.

Como se citó, cualquier intervención gubernamental que active la demanda efectiva de manera de aumentar la producción y, en consecuencia, reducir el desempleo más allá de su tasa natural, no solo no lograría este resultado sino que aceleraría la inflación. Pero si en una economía esta tasa natural de desempleo fuera muy alta o, como ocurre en los países en desarrollo, aunque fuera baja podría estar enmascarando una situación de desempleo disfrazado, entonces esta economía estaría condenada a no poder corregir esta situación, pues no tendría sentido activar la demanda, como Keynes y sus seguidores siempre han propuesto. ${ }^{16}$

Desde la perspectiva de la ortodoxia mainstream podrían plantearse algunas soluciones que reduzcan el desempleo en todas sus manifestaciones.

Según la teoría ortodoxa, son un conjunto de rigideces estructurales las que impiden que el mercado laboral actúe eficientemente y logre el equilibrio con pleno empleo. Por consiguiente si no se eliminan estas rigideces y se intenta aplicar por ejemplo políticas activistas de demanda, solo se lograría impulsar de manera creciente la inflación. Por el contrario, las políticas gubernamentales e institucionales no deben ser intervencionistas sino más bien orientarse a eliminar efectivamente las trabas que dificultan la libre acción de los actores que participan en el mercado de trabajo y así reducir el desempleo, siendo al mismo tiempo neutrales en materia fiscal y monetaria. 
Pero hay otra cuestión importante. Como sostuviera Keynes (op. cit.) la condición previa para alcanzar el pleno empleo es que en toda sociedad el ingreso y la riqueza se distribuyan equitativamente, ya que, de hecho, cualquier política económica, en particular aquellas que activen la demanda, necesariamente redistribuirá ambos.

Para la ortodoxia, garantizar que el mercado de trabajo funcione eficientemente; vale decir, sin trabas, podría tener posiblemente efectos no deseados en términos de distribución, pero podría utilizarse un conjunto de medidas orientadas a lograr la equidad que complementen la acción del mercado, asignando por ejemplo a los salarios un rol equilibrador. Un efecto redistributivo sobre la base de un mercado sin rigideces sería mejor que el que se genere por políticas activistas de demanda que alimentan la inflación.

Una propuesta de complementación de ingresos laborales que puede citarse, completamente ajena de cualquier política de estímulo a través de manipular la demanda agregada, es la planteada por diversos economistas ortodoxos entre ellos Friedman (1962). Esta propuesta es la de fijar un "Ingreso Garantizado", complementando las remuneraciones de aquellos que ganan poco y que, a diferencia por ejemplo del sistema de remuneración compensatoria al desempleado ("Welfare"), o del salario mínimo vital o básico, distorsionaría mucho menos el funcionamiento del mercado laboral y no rigidizaría los salarios. La base de esta propuesta radica en que a todos los trabajadores se les debe garantizar un salario mínimo básico. En síntesis, la idea sería complementar el ingreso de un trabajador empleado en el sector privado que recibe bajos salarios hasta que su remuneración alcance un nivel que le permita cubrir su canasta básica de consumo.

Pero en este caso, cualquier trabajador buscaría, en principio, ubicarse en un puesto de trabajo en el sector privado independientemente del salario que le paguen, pues sabe que la diferencia sería cubierta por el programa de ingresos garantizados. Esto podría evidentemente hacer crecer de manera importante la tendencia a aceptar remuneraciones bajas y a trabajar solo a tiempo parcial.

Una actitud como ésta generaría presiones a la baja en los salarios, con el agravante de que si hubiera desempleo, podría acelerarse esta tendencia deflacionaria en los salarios y podría ocurrir además que aquellos 
trabajadores que sí cuentan con un puesto de trabajo no tendrían mayores problemas para aceptar rebajas en sus remuneraciones en el caso de una reducción en la demanda laboral, con lo que se retornaría a la idea, criticada por Keynes, de que los salarios serían, en estas circunstancias, flexibles a la baja.

Si una economía enfrentara una reducción continua y significativa en los salarios, ello podrías exigir un aumento continuo en el esfuerzo compensatorio del gobierno para impedir que la demanda agregada se desplome debido a la caída salarial, lo que evidentemente haría peligrar la continuidad de un programa compensatorio de este tipo.

Entonces ¿qué se puede hacer?

Para responder a esta pregunta sería necesario presentar alternativas a la forma como la ortodoxia Neoclásica estableció las reglas de comportamiento del mercado de trabajo, con el fin de encontrar posibles soluciones que permitan lograr el pleno empleo con salarios justos.

\section{A. El Mercado de Trabajo Neoclásico}

En el mercado de trabajo Neoclásico tradicional, como es conocido, se determina simultáneamente el equilibrio de la cantidad de mano de obra y el nivel de salario real en condiciones de pleno empleo y, tradicionalmente, de libre competencia. Se acepta, en general, que ocurre un ajuste instantáneo frente a cualquier alteración de las condiciones de equilibrio con pleno empleo y donde los precios y salarios son perfectamente flexibles, de manera que el mercado de trabajo siempre está en equilibrio. Ello ocurre, como sabemos cuando la función de oferta de mano de obra, usualmente de inclinación positiva a todo lo largo y la función de demanda de mano de obra, de inclinación negativa, se encuentran, de manera que el salario real determinado por el cruce de ambas funciones es aquel que deja satisfechos a demandantes y oferentes, ofreciendo y demandando exactamente la cantidad de trabajo fijado en el punto de cruce mencionado.

Como es también bastante familiar, la curva de demanda laboral tiene pendiente negativa debido a los valores que adopta la productividad marginal de la mano de obra en virtud de la aplicación de la ley de 
rendimientos decrecientes. Así, los demandantes de trabajo (las empresas), bajo el supuesto que el fin que persiguen es la maximización de su utilidad, logran dicha maximización cuando contratan una cantidad de mano de obra que haga que el producto marginal de la misma iguale al salario que, en términos reales, fija el mercado y que, debido a asumir libre competencia, es un dato para tales demandantes (son "tomadores de precios").

A su vez, la curva de oferta de trabajo se basa en el supuesto que los oferentes de mano de obra (los trabajadores), maximizan una función de utilidad compuesta de dos "bienes": ingreso y tiempo libre. Así, a partir del salario real que fija el mercado, que es nuevamente un dato para los oferentes, ellos combinan la cantidad de ingreso que reciben por trabajar con las horas que están dispuestos a reservarse como tiempo libre, de manera de alcanzar la máxima satisfacción. Es importante señalar que en esta conceptualización el trabajo es un sacrificio en el que se tiene que incurrir para lograr el ingreso necesario para mantenerse, de manera que el salario representa la compensación por la desutilidad que implica trabajar. Dejando de lado la crítica obvia que el trabajo, en general, no genera necesariamente insatisfacción, ni es un "castigo", la forma en que se determina la curva de oferta de trabajo, bajo las condiciones señaladas, presenta una particularidad: que es "doblante hacia atrás"; vale decir, que si se parte de salarios bajos a medida que el salario sube los trabajadores están dispuestos a trabajar más horas, en una relación directa que determina la inclinación positiva de la oferta de trabajo. Sin embargo, a altos niveles de salario, la oferta empieza a "doblarse hacia atrás" (a inclinarse negativamente) para representar una situación en que al aumentar éstos a partir de niveles ya altos, el trabajador reduciría la cantidad que está dispuesto a trabajar y aumentaría las horas dedicadas al tiempo libre. Esta parte de la oferta laboral de inclinación negativa generalmente no se toma en cuenta en los análisis convencionales.

Lo interesante aquí es que el equilibrio, con pleno empleo, que se obtiene cuando ambas curvas se cruzan, bajo los supuestos antes citados, jamás se alterará pase lo que pase en el resto de la economía. Así, si por ejemplo el salario real estuviera debajo de aquel nivel que garantiza el pleno empleo, debido a un alza de precios, la competencia entre empresarios elevaría el salario nominal hasta igualar el alza en los precios 
de manera de restituir el equilibrio con pleno empleo. Lo opuesto ocurriría ante una baja en el nivel de precios: En este caso la competencia entre los trabajadores reduciría el salario nominal hasta que se restituya el salario real que lleve al mercado nuevamente a su equilibrio con pleno empleo.

Es importante notar que las características presentadas, en particular sobre la forma e inclinación de las funciones de oferta y demanda de trabajo no han cambiado esencialmente en las versiones de la ortodoxia neoclásica moderna que incluyen las diversas formas de expectativas; $y$, que como se vio al principio del presente trabajo, el equilibrio de pleno empleo que fija el mercado no se alterará bajo la acción de políticas que actúen sobre la demanda agregada

\section{B. El mercado de trabajo poskeynesiano, una alternativa a la ortodoxia}

La visión Poskeynesiana, que difiere significativamente de la ortodoxia respecto al mercado de trabajo y que aquí se comparte, debe evaluarse, al menos para el enfoque que se presentará, teniendo en cuenta dos consideraciones. La primera, una concepción completamente diferente de la demanda de mano de obra y la segunda, la inclusión de la parte "volteante hacia atrás" de la oferta de trabajo.

Esto plantea la posibilidad de que en el mercado de trabajo exista más de una posición de equilibrio, lo que a su vez plantea distintas formas de análisis y conclusiones que difieren de las propuestas por la ortodoxia Neoclásica. Plantea en particular la posibilidad que si se deja al mercado actuar libremente, se llegue a situaciones de equilibrio con muy bajos salarios y altos niveles de desempleo, en particular de desempleo disfrazado. Si, como ya se vio, una situación como está implica una tasa natural de desempleo elevada nada podría hacerse para reducirla, a menos que se cambien las reglas planteadas por la ortodoxia y eso es lo que a continuación se debe considerar.

i. La Demanda de Trabajo Poskeynesiana

La mayoría de autores Poskeynesianos han redefinido la forma como se deduce la demanda de trabajo que, como ya se mencionó, difiere di- 
ametralmente de la visión ortodoxa. Ellos rechazan la idea que dicha demanda se base en los conceptos de maximización de utilidades, de la ley de rendimientos decrecientes, de las productividades marginales y, de la libre competencia.

Su deducción de la demanda laboral se basa en un esquema de análisis derivado de MichalKalecki, que es consistente con las consideraciones de Keynes después de la Teoría General, en el sentido de asumir, posiblemente de manera más cercana a la realidad, que las firmas fijan los precios (no son, como en el caso de libre competencia "tomadores de los precios" que establece el mercado bajo libre competencia), vía el mark-up (agregando, como se dijo antes, a los costos un margen predeterminado de ganancia); esto es, aceptándose que ellas operan en competencia imperfecta y, a la Kalecki, considerando que los costos unitarios (los denominados costos directos) son prácticamente constantes.

Hay diversas formas analíticas de deducir la demanda laboral, que arriban a la misma conclusión: la cantidad demandada de mano de obra es una función creciente de los salarios.

Una de estas presentaciones es la formulada por Lavoie (2000):

Se asume que las firmas contratan dos tipos de trabajadores: aquellos (la mayoría) cuya cantidad varía directamente con el volumen de la producción, que se puede representar por $\mathbf{N}_{\mathbf{v}}$ (mano de obra variable) y el resto (la minoría) que está en relación directa con el tamaño de la planta e instalaciones de la empresa; vale decir, aquella cuya función es administrativa, que se representaría como $\mathbf{N}_{\mathbf{k}}$. Dado que el análisis se lleva a cabo para el corto plazo, para el cual se asume que el tamaño de planta y el equipo son fijos, se infiere que el segundo grupo de trabajadores es también fijo.

Así, la cantidad total de trabajadores empleados $\mathbf{N}$, está compuesta de los dos tipos de trabajadores mencionados; esto es: $\mathbf{N}=\mathbf{N}_{\mathbf{v}}+\mathbf{N}_{\mathbf{k}}$ que reciben salarios diferenciados, correspondiendo $\mathbf{w}_{\mathbf{v}}$ a los trabajadores de demanda variable y $\mathbf{w}_{\mathbf{k}}$ a los de demanda fija de manera que el salario total promedio (w), sería igual a $\mathbf{w}_{\mathbf{v}}+\mathbf{w}_{\mathbf{k}}$. Adicionalmente, como $\mathbf{N}_{\mathbf{v}}$ es variable con respecto a la producción, se tiene que: $\mathbf{Y}=\boldsymbol{\alpha} \mathbf{N}_{\mathbf{v}}$; de manera que $\mathbf{N v}$ $=\mathbf{Y} / \boldsymbol{\alpha}$, donde $\mathbf{Y}$ es la producción real y $\boldsymbol{\alpha}$ es la productividad de la mano 
de obra variable, productividad que se asumirá constante. Esta ecuación representa la función de producción. Alternativamente, la función de producción se puede escribir de la siguiente forma:

$$
\mathbf{Y}=\left(\mathbf{N}-\mathbf{N}_{\mathrm{k}}\right) \boldsymbol{\alpha} \text {. }
$$

A partir de lo expuesto se puede definir a la Oferta Agregada como:

$$
\mathrm{OA}=\mathrm{PY}=\mathrm{P}(\mathrm{N}-\mathrm{Nk}) \alpha
$$

Donde $\mathbf{P}$ representa al nivel de precios. Paralelamente, se puede considerar a la demanda agregada como:

$$
\mathrm{DA}=\mathbf{w N}+\boldsymbol{\beta P}
$$

Que es una versión bastante simplificada que asume a la demanda agregada como compuesta de dos elementos: el total de salarios pagados $(\mathbf{w N})$ y el valor monetario de los gastos exógenos ( $\beta \mathbf{P})$, que incluyen tanto los gastos de inversión ${ }^{17}$ como la porción de las utilidades empresariales destinadas al consumo. Se asume asimismo que los trabajadores gastan todo su ingreso en los gastos de consumo. ${ }^{18} \mathrm{La}$ demanda agregada puede reescribirse como:

$$
D A=w_{v} N_{v}+w_{k} N_{k}+\beta P
$$

Adicionalmente, se asume que los trabajadores "fijos" (administrativos) ganan más que los trabajadores variables. Esto puede representarse como que $\mathbf{w}_{\mathbf{k}}=\boldsymbol{\varphi} \mathbf{w}_{\mathbf{v}}$, siendo $\varphi$ mayor que la unidad.

Como se mencionara arriba, los economistas Poskeynesianos han afirmado siempre que la demanda de mano de obra depende fundamentalmente de la demanda efectiva, a través de la interacción de esa última con la oferta agregada y no de consideraciones asociadas a los costos e ingresos marginales y/o a la maximización de los beneficios.

En consecuencia, igualando la oferta y demanda agregadas ${ }^{19}$ se tendría la ecuación de la demanda por mano de obra (la demanda efectiva de mano de obra según Lavoie), expresada por la relación entre la tasa básica del salario real (la pagada al trabajo variable) y el nivel agregado de empleo (Lavoie, op. cit. p. 46): 


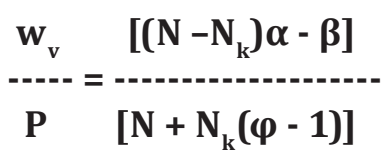

Según Lavoie (op. cit., p. 46), en (5) la primera derivada con respecto a $\mathrm{N}$ es positiva y asintótica al índice de productividad variable $(\boldsymbol{\alpha})$. En consecuencia, la cantidad de mano de obra variable estaría en relación directa con los salarios reales que se les paga. Esto es, la función que relaciona a la demanda de mano de obra con el salario real es creciente (crece al subir el salario de los trabajadores variables y consecuentemente el de los trabajadores administrativos fijos), a diferencia de lo postulado por la ortodoxia Neoclásica que establece que dicha relación es inversa y, consecuentemente, su curva de demanda de empleo es una función decreciente del salario real. El hecho que la función sea asintótica a $(\boldsymbol{\alpha})$ indica que esta productividad sería el límite máximo al que debería llegar el salario real, ya que si este límite fuera superado, ocurriría que dicha productividad (la ganancia por unidad de $\mathbf{N}_{\mathbf{v}}$ utilizada) sería inferior a su costo unitario real $\left(w_{v} / P\right)$.

Estos resultados se pueden apreciar en el siguiente gráfico 3 inspirado en Lavoie (op. cit.,p. 47, Gráfica 9) y en Seccareccia (Mario Seccareccia, "WhatType Of Full Employment?A CriticalEvaluation of "Government as theEmployer of Last Resort" PolicyProposal, enInvestigación Económica, Vol. LXIII, 247, enero-marzo, 2004, p. 27, Figure 2).

En consecuencia, comenzando con la dotación fija a corto plazo de trabajadores administrativos $\left(\mathbf{N}_{\mathbf{k}}\right)$ es posible alcanzar el pleno empleo elevando el salario real, como se indicó antes y como se aprecia en el gráfico, hasta el límite fijado por la productividad de la mano de obra variable $(\boldsymbol{\alpha})$. Bajo este análisis resulta interesante observar que una reducción en los salarios no solo no aumentaría el nivel de empleo sino que lo reduciría.

Versiones alternativas sobre la relación entre el salario real y la demanda por mano presentadas por otros economistas Poskeynesianos, arriban a las mismas conclusiones: que la relación entre la demanda de mano de obra y los salarios reales es creciente y, consiguientemente, la curva de demanda laboral es de inclinación positiva y asintótica al coeficiente de la productividad de la mano de obra. 


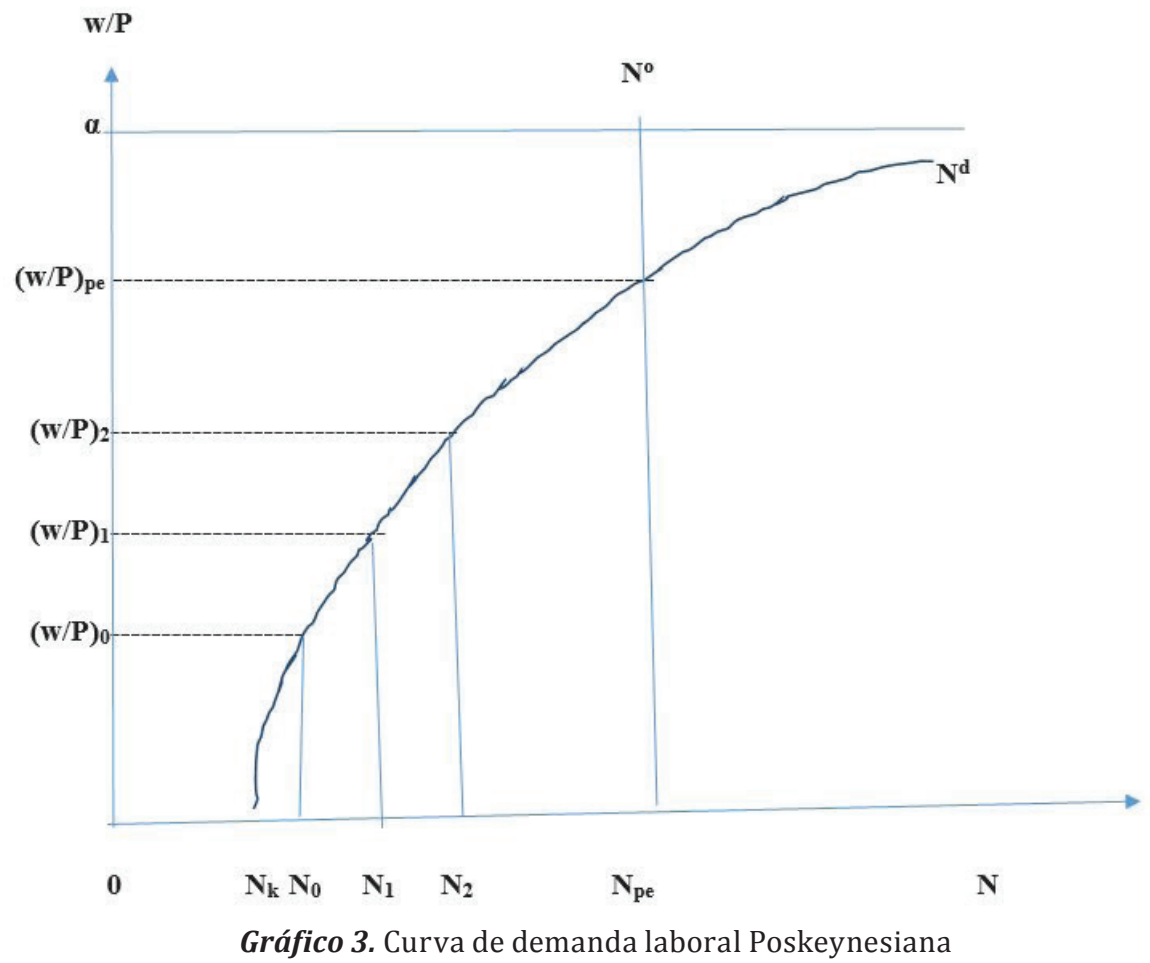

Así, Seccareccia (op. cit. pp. 25 y 26), parte de la dependencia del ingreso real agregado (Y) de los gastos en consumo (C), de las inversiones del sector privado (I), del Déficit Fiscal (D) y de las Exportaciones Netas (EN):

$$
\mathrm{Y}=\mathrm{C}+\mathrm{I}+\mathrm{D}+\mathrm{EN}
$$

Considera a continuación que el ingreso puede ser clasificado según la fuente de origen: en el que se deriva del trabajo (wN), donde $\mathbf{w}$ es el salario real promedio de los sectores público y privado y $\mathbf{N}$ la cantidad de trabajo, y el que procede de la propiedad (R), que agrega el flujo de intereses, rentas y utilidades:

$$
\mathbf{Y}=\mathbf{w N}+\mathbf{R}
$$


Además, asume que en $\mathbf{C}$ (la función consumo), $\boldsymbol{\Psi}$ es la propensión a consumir del ingreso laboral y $\boldsymbol{\theta}$ la del ingreso de la propiedad, considerando que $\boldsymbol{\psi}$ es mayor que $\boldsymbol{\theta}$ :

$$
C=\Psi(w N)+\theta R
$$

Considerando el caso extremo que $\boldsymbol{\theta} \mathbf{R}=\mathbf{0}$, asumiendo una función de utilización lineal como $\mathbf{Y}=\boldsymbol{\mu} \mathbf{N}$, haciendo $(\mathbf{I}+\mathbf{D}+\mathbf{E N})=\mathbf{Z}$ (gasto exógeno) y reemplazando convenientemente:

$$
\mu N=\Psi(w N)+Z
$$

Reorganizando esta ecuación es posible obtener la curva agregada de demanda por mano de obra:

$$
\mathrm{N}=\frac{1 / \mu}{1-\psi w / \mu}
$$

Donde, nuevamente, es fácil apreciar la relación directa y no lineal, entre w (salario real) y $\mathbf{N}$ (demanda de mano de obra). Se puede ver también, como expresa Seccareccia, que si cae $\boldsymbol{\mu}$ o aumenta $\boldsymbol{\psi}$ y/o $\mathbf{Z}$, la curva de demanda se desplazará hacia la derecha y/o cambiaría su pendiente. ${ }^{20}$

ii. Equilibrio Poskeynesianoen el Mercado Laboral

El equilibrio en el mercado laboral se fija, como es usual, en el punto donde se cruzan la oferta y la demanda por mano de obra. En la versión Poskeynesiana, el equilibrio se verifica en el cruce de la curva de demanda por mano de obra de pendiente positiva, tal como la deducida arriba, con la curva de oferta de trabajo que incluye la parte "volteante hacia atrás" de esta última que ocurre a elevados niveles de ingresos reales.

La diferencia fundamental del análisis Poskeynesiano con el de la ortodoxia Neoclásica radica en que el equilibrio en el mercado laboral no es único, tal como se aprecia en el siguiente gráfico, inspirado en Lavoie (op. cit., p. 50, Gráfica 10) y en Seccareccia (op. cit., p. 29, Figure 3) y ello plantea la posibilidad de conclusiones significativamente diferentes a las presentadas por la ortodoxia. El análisis Poskeynesiano tendría la gran ventaja de independizarnos de la "tiranía" de la tasa natural de desempleo y justificaría la intervención del estado como empleador. 


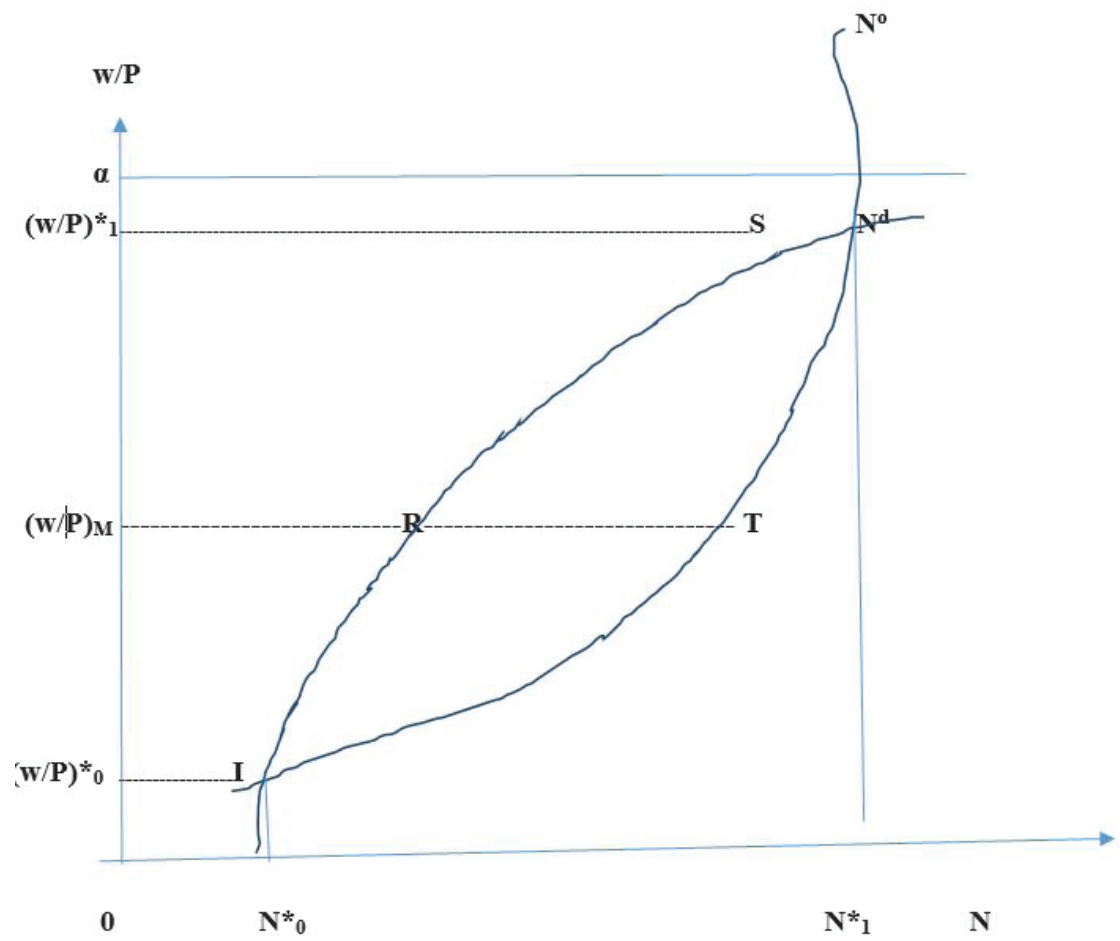

Gráfico 4. Equilibrio Poskeynesiano en el mercado de trabajo

Como se aprecia en este gráfico 4, ocurrirían dos posiciones de equilibrio en el mercado de trabajo. La superior (S), con niveles de ocupación $\left(\mathbf{N}^{*}\right.$ ) cercanos al pleno empleo y alta tasa de salarios reales $\left[(\mathbf{W} / \mathbf{P})^{*}{ }_{1}\right]$ y la inferior (I)con reducidos niveles de empleo $\left(\mathbf{N}_{\mathbf{0}}^{*}\right)$ y muy bajos salarios reales $\left[(\mathbf{w} / \mathbf{P})^{*}{ }_{0}\right]$. Siguiendo el enfoque Poskeynesiano, la primera posición representaría bastante bien una situación en la que la gran mayoría de trabajadores estarían gozando de salarios altos y estándares elevados de satisfacción de necesidades, con prácticamente ausencia de desempleo (con una "tasa natural de desempleo" muy baja) y nula informalidad. Por el contrario, la segunda posición mostraría un equilibrio con un alto desempleo formal y muy bajos salarios reales (con una "tasa natural de desempleo" muy alta) y con un nivel muy elevado de desempleo disfrazado o subempleo informal. La segunda posición estaría ilustrando, en particular, el caso peruano y, dado que esta situ- 
ación representaría también una alta tasa natural de desempleo, no habría forma, al menos en la concepción de la ortodoxia Neoclásica, de reducir esta tasa natural mediante políticas económicas que activen la demanda agregada.

Como se puede observar en el gráfico, el "bolsón" que se forma entre las dos posiciones de equilibrio laboral mencionadas constituiría una fuerza de trabajo informal (deuna "reserva potencial de trabajo") que estaría constituida, como ya se señaló, por dos grupos de trabajadores: uno, que incluye a aquellos que han abandonado la fuerza laboral "regular" y han pasado a formar parte de la informalidad (desempleo "disfrazado") y el otro, que comprende a los que están (al salario real menor) en desempleo involuntario (desempleo "abierto"). ${ }^{21}$ En el gráfico, a manera de ejemplo, se ilustra la distancia RT como el máximo volumen de desempleo abierto y subempleo.

En términos del enfoque Poskeynesiano, si se dejara que el mercado actuara libremente, sería muy difícil alcanzar la posición de equilibrio con altos ingresos y muy bajo desempleo, debido a que la dinámica de las fuerzas del mercado harían que, de las dos posiciones de equilibrio presentadas, la segunda sea la única estable, determinando un bajo nivel de vida. Por ello, la intervención del estado resultaría fundamental para lograr mejorar la calidad de vida de los trabajadores y la reducción del desempleo disfrazado.

\section{Una solución sugerida por el poskeynesianismo: la inter- vencion del estado como empleador de ultimo recurso}

A partir de la redefinición de la forma como se representarían las fuerzas que actúan en el mercado de trabajo en el contexto del Poskeynesianismo que, como se ha apreciado, presenta diferencias importantes respecto a la interpretación de la ortodoxia mainstream, se pueden plantear posibles soluciones para alcanzar un pleno empleo a un nivel de salarios reales, social y económicamente adecuados.

Una de estas propuestas, que parece sumamente interesante y sugerente es la planteada, entre otros autores Poskeynesianos, por Hyman P. 
Minsky, Larry Wray y más recientemente, por Mario Seccareccia (op. cit.), a quien se seguirá en lo fundamental de su propuesta.

El planteamiento radica en hacer que el estado se constituya en "empleador de último recurso, de última instancia". Esta alternativa resulta relevante porque rehabilita el rol del estado como actor clave en la contratación directa de mano de obra, en particular de aquella que el sector privado tiene dificultad en absorber. En consecuencia, no deja exclusivamente al mercado la solución de la falta de empleo, como lo plantea la ortodoxia. Recuperaría además el significado que un puesto de trabajo y una remuneración adecuados tienen para el bienestar.

El programa (en adelante Programa EUR) plantea, en esencia, que el gobierno fije exógenamente un nivel de salario real de "último recurso" $\left(\mathbf{w}_{\text {ur }}\right)$ para remunerar a la mano de obra que el programa EUR contrate. Este $\mathbf{w}_{\text {ur }}$ pasaría a ser parte (y ayudaría a fijar) un valor específico $\mathbf{w}^{\mathbf{p p}}{ }_{\text {ur }}$ que representaría el promedio ponderado del salario EUR para toda la economía. El programa asume además, que en el corto plazo, los cambios en el $\mathbf{w}_{\text {ur }}$ no generarían necesariamente cambios significativos en el nivel de precios. Utilizando un gráfico similar al que se incluye a continuación, Seccareccia (op. cit., p. 30, Figure 4) explica como opera el programa.

En el gráfico, $(\mathbf{w} / \mathbf{P}){ }_{0}{ }_{0} \mathrm{y}(\mathbf{w} / \mathbf{P}){ }_{1}{ }_{1}$ representan respectivamente dos posiciones de equilibrio con pleno empleo. El primero $\mathbf{N}_{0}^{*}$ (punto I) no muestra el elevado volumen de desempleo disfrazado o subempleo representado por la distancia $\left(\mathbf{N}_{0}^{*}-\mathbf{N}_{1}^{*}\right)$, en tanto que un pleno empleo con cero informalidad $\left(\mathbf{N}^{*}\right.$ ) ocurre (punto $\mathbf{S}$ ) a un salario de $(\mathbf{W} / \mathbf{P}){ }_{1}{ }_{1}$. Como se aprecia, entre los puntos I y $\mathbf{S}$, se ha graficado un "bolsón" que representaría diversos volúmenes de desempleo (abierto y disfrazado).

Inicialmente, con fines diagramáticos, se fija un piso inicial para $\mathbf{w}_{\text {ur }}$ que determina en promedio un $\mathbf{w}^{\mathbf{p p}}{ }_{\text {ur }}$ Tal salario es $\mathbf{w}^{\mathbf{p p}}{ }_{\text {ur(M) }}$ donde la brecha del "bolsón" es la más grande; esto es, donde es mayor la diferencia entre la oferta y la demanda de trabajo (la distancia RT), que representa también la cantidad máxima de desempleo (abierto y disfrazado) que tendría que absorber el programa EUR. Así, al inicio de la aplicación del programa el mercado de trabajo se encontraría en equilibrio en el punto $\mathbf{T}$ (en la tangencia de las curvas de oferta $\mathbf{N}^{s} \mathrm{y}$ demanda laboral $\mathbf{N}_{0}^{\mathbf{d}}$ ). El gasto del gobierno para emplear al total de 
desempleados en esta circunstancia desplazaría la curva de demanda por mano de obra de $\mathbf{N}_{0}^{\mathrm{d}}$ a $\mathbf{N}_{1}^{\mathrm{d}}$.

En cualquier otro punto encima o debajo de $\mathbf{T}$ (entre I y $\mathbf{S}$; esto es, con un salario real promedio diferente a $\mathbf{w}^{\mathbf{p p}}{ }_{\operatorname{ur}(\mathrm{M})}$ ), como en $\mathbf{T}^{\prime}$, (donde el salario a fijar sería mayor) ambas curvas se cruzarían. En un punto como $\mathbf{T}$ ', es fácil observar que al ser menor la cantidad de desempleo (de los dos tipos), el gasto gubernamental para la absorción del desempleo sería menor. Este menor gasto se representa en el gráfico por el desplazamiento de la curva $\mathbf{N}^{\mathbf{d}}$ no hasta $\mathbf{N}^{\mathrm{d}}{ }_{1}$ sino hasta una distancia menor (hasta $\left(\mathbf{N}_{2}^{\mathbf{d}}\right)$. Ello sería también verdad para cualquier punto debajo de $\mathbf{T}$, aunque a niveles inferiores de $\mathbf{w}^{\mathbf{p p}}{ }_{\text {ur(M) }}$. En suma, para cualquier salario mayor o menor que $\mathbf{w}^{\mathbf{p p}}{ }_{\text {ur }}$ el gasto de absorción sería menor. Pero, como enfatiza el autor citado, aunque en ambos casos este gasto sea menor, el costo social sería evidentemente diferente. De hecho, reducir el bolsón fijando un alto es $\mathbf{w}^{\mathbf{p p}}$ ur mayor sería socialmente mejor, al permitir mejores condiciones de vida para los trabajadores.

Un aspecto importante que el autor rescata es el hecho que cuanto más bajo quede fijado $\mathbf{w}^{\mathbf{p p}}$ ur conduciendo a la economía hacia el punto I (y al muy bajo salario $\mathbf{w} / \mathbf{P}_{0}^{*}$ ), mayor sería el nivel de desempleo disfrazado (subempleo). Por ejemplo, si el gobierno fijara un $\mathbf{w}_{\text {ur }}$ que en promedio resultara estableciendo un $\mathbf{w}^{\mathbf{p p}}$ ir igual a $\mathbf{w} / \mathbf{P}^{*}$ (el más bajo en el gráfico), la gran mayoría (sino todos) los trabajadores preferirían pasar a la informalidad. Esto es, si el gobierno fijara para el programa un salario demasiado bajo, probablemente éste no sería aceptado por los trabajadores que preferirían permanecer (o incorporarse) a la informalidad. Lo opuesto ocurriría si el salario $\mathbf{w}^{\mathbf{p p}}$ ur resultaría fijado cerca del punto $\mathbf{S}$ (cerca del salario alto $\mathbf{w} / \mathbf{P}^{*}{ }_{1}$ ), ya que, como se mencionó antes, el desempleo sería menor y, en principio, el esfuerzo de absorción gubernamental menos costoso (respecto a la situación prevaleciente en el punto T). En esta circunstancia, siw $w_{\text {ur }}$ altos empujan al alza los salarios reales de la economía, se alcanzaría el pleno empleo pero con un "bolsón cero" (en el punto S) y ya no sería necesario continuar aplicando el programa EUR.

A partir de lo planteado, Seccareccia (op. cit., p. 30) concluye que la elección gubernamental del $\mathbf{w}_{\mathbf{u r}}$ (que fije luego el promedio ponderado $\mathbf{w}^{\mathbf{p}-}$ ${ }_{\text {ur }}$ ) resulta crucial. Esta elección determinará si la economía alcanza una 
situación de pleno empleo con un muy bajo $\mathbf{w}_{\text {ur }}$ y con una pérdida significativa de recursos (alto desempleo abierto y disfrazado), u otra de altos salarios y cero desempleo. Como se expresara antes, es evidente que la primera elección tendría un muy alto costo social.

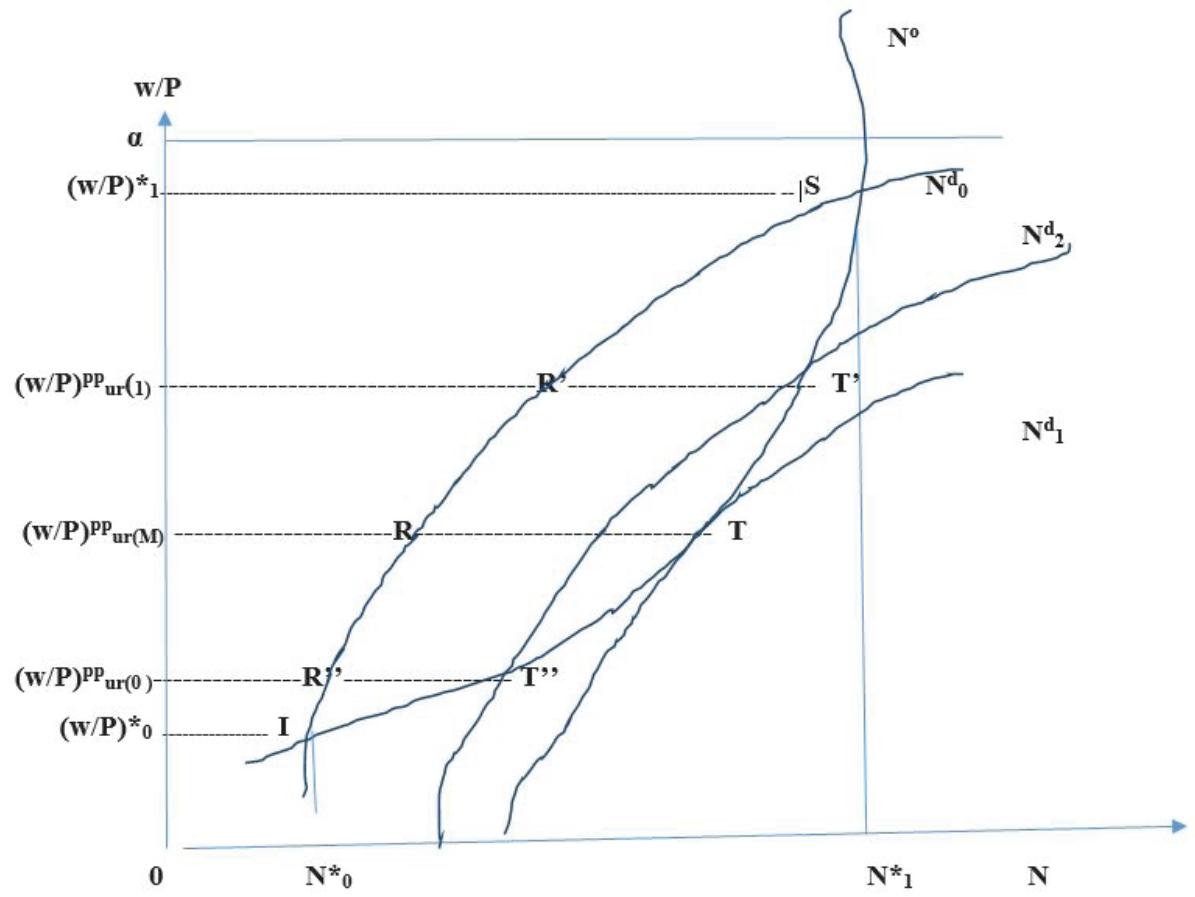

Gráfico 5. Aplicación del programa EUR

Otro aspecto de especial relevancia es aquel que se refiere a los posibles efectos inflacionarios o deflacionarios que tendría el fijar $\mathbf{w}_{\mathbf{u r}}$ muy altos o muy bajos. Como se indicó antes, se asume que la implementación del programa EUR, por lo menos a corto plazo, no debería afectar los salarios (y los precios) de todos los otros sectores (tanto públicos como privados); pero, esto nuevamente dependerá del valor inicial que el gobierno fije para $\mathbf{w}_{\text {ur }}$. Es posible que cuanto mayor sea este valor más probable será que presione al alza todos los salarios y precios de la economía. Seccareccia considera sin embargo que este efecto dependerá de cuan importante sea, entre otras cosas, el comercio exterior del país. Si este es el caso, las empresas que enfrenten 
alzas de salarios preferirán, a fin de mantener su competitividad externa y no perder mercados, reducir su margen de utilidad sin elevar sus precios, al menos en el corto plazo, evitando así una inflación por empuje de costos. Las empresas recuperarían sus utilidades en el largo plazo mediante la reducción de costos unitarios de producción incrementando su productividad.

El autor no niega que la fijación de elevados niveles de $\mathbf{w}_{\text {ur }}$ podría tener un sesgo inflacionario, sobre todo si se lo fija muy alto; sin embargo, cita a Larry R. Wray ${ }^{22}$ quien argumenta que un sistema EUR no acelera la inflación. Lo que puede ocurrir es que el programa pueda dar lugar a un alza de salarios y precios "de una sola vez" y no ejercer un "cambio continuo y sostenido" en los mismos.

La conclusión más importante de lo que hasta aquí se ha analizado es que es posible reducir el desempleo (abierto y disfrazado) y elevar los salarios con la participación activa del gobierno actuando como "empleador de último recurso" (participando directamente), contradiciendo abiertamente las conclusiones de la ortodoxia Neoclásica que hace inútil e innecesaria esta participación ya que solo originaría inflación sin corregir el desempleo representado por la "tasa natural" (la NAIRU), la que podría esconder un fuerte porcentaje de desempleo disfrazado que según el análisis Neoclásico no podría ser reducido o eliminado.

Así, es tiempo ya de reconocer que la intervención activa del gobierno es relevante para mejorar la calidad de vida de los ciudadanos ofreciendo directamente un puesto decente de trabajo y reconsiderar las políticas que durante mucho tiempo han conducido a una creciente austeridad recesiva diseñada para enfrentar una amenaza inflacionaria que podría no ser tal.

i. Una forma posible de programa gubernamental EUR: El reacondicionamiento ("Overhauling") del parque automotriz

La ausencia en el país de una política de sustitución de vehículos antiguos (de diversos tipos, públicos y privados) y el considerable y continuo aumento en el parque automotriz, junto a la prácticamente nula ampliación y mejora de las vías de comunicación, exige adoptar medidas urgentes. En este sentido, podría ser interesante estudiar la posibi- 
lidad de una intervención directa del estado como EUR en, por ejemplo, el establecimiento de un conjunto de plantas de reacondicionamiento del parque automotor, distribuidas estratégicamente en todo el país. Las partes que actualmente no pueden sustituirse como motores semiarmados se importarían a gran escala directamente mediante convenios gobierno a gobierno con países productores, según las especificaciones técnicas que resulten más adecuadas y a precios convenientes. El resto de componentes podrían reacondicionarse, donde sea posible, usando partes y piezas de fabricación nacional, sujetas a estricto control de calidad. Los no interesados en repotenciar sus unidades podrían venderlas directamente al estado, según normas a establecer y los que si lo están podrían incorporarse como usuarios del programa de mejora de los vehículos, pagando el costo del reponteciamiento, que se asociaría al grado de deterioro y/o antigüedad de la unidad.

Estimamos que las ventajas de un programa gubernamental como el planteado serían muchas:

1. Previo un breve periodo de entrenamiento, se podría reducir el desempleo (abierto y disfrazado) en este rubro, pagándose salarios del tipo y en la forma mencionados arriba $\left(\mathbf{w}_{\mathbf{u r}}\right)$, a los trabajadores de las plantas y aumentando la demanda de partes y piezas a proveedores nacionales, generando empleos indirectos. Inicialmente podría fijarse el salario en(w/P) ${ }^{\mathbf{p p}}{ }_{\text {ur(M) }}$ ) del Gráfico 5, de manera de absorber directamente la mayor cantidad de desempleo y subempleo.

2. Se renovaría significativamente el parque automotriz sin aumentar necesariamente el número de unidades nuevas, especialmente las de servicio público y carga, lo que reduciría la presión sobre la infraestructura vial, mejorando la calidad del servicio

3. El precio de un vehículo repotenciado (prácticamente nuevo) debería ser considerablemente inferior a uno nuevo importado y permitiría al gobierno recuperar progresivamente los recursos utilizados en la importación de las partes actualmente no sustituibles, para continuar usándolos en futuras importaciones. 
4. Los trabajadores directos, gracias al continuo entrenamiento de "aprender haciendo" podrían en el futuro sustituir las piezas que al principio se importen, por unas de fabricación nacional.

Consideramos que un programa de este tipo tendría que aplicarse básicamente a los vehículos antiguos dedicados al transporte público (taxis, microbuses y buses), así como al transporte de carga y vehículos oficiales. Respecto a los vehículos de uso privado, se debería diseñar mecanismos que hagan más atractivo (además del precio) adquirir un vehículo repotenciado que importar uno nuevo.

\section{Reducir tanto el desempleo como la inflación mejoran el bienestar, pero ¿cual priorizar?}

La política económica en el Perú, por lo menos en los últimos treinta años, no ha estado orientada a abordar directamente el problema que para el bienestar constituye el desempleo disfrazado, el empleo informal. Proporcionar un trabajo digno y una remuneración adecuada siempre se ha dejado a la iniciativa del sector privado, estimulando por todos los medios la inversión privada, como el vehículo obvio para lograrlo. Lamentablemente, la excesiva confianza en dejar a la iniciativa del libre mercado, a su eficiencia, la solución de este problema, parece que no ha dado resultado. Por ello, consideramos que es tiempo de abordar las cosas de manera diferente. Una de estas formas podría ser la planteada aquí: que el estado actúe directamente, como un empleador de último recurso, pues como se ha expuesto líneas arriba, podría mejorar el bienestar sin generar efectos inflacionarios significativos.

Posiblemente la falta de entusiasmo para abordar el problema en formas como la descrita se encuentra en un escollo difícil de superar: nuestra dependencia en la manera ortodoxa de abordar los problemas económicos. Bajo sus postulados la prioridad es contener la inflación, ya que según el mainstream el control adecuado de la inflación ayudaría a resolver el resto de problemas, entre ellos los del desempleo abierto y disfrazado y, de manera automática, alcanzar la producción potencial con pleno empleo. Esta visión que muchos han calificado como "la Divina Coincidencia" se acepta ahora que no es correcta y podría funcionar en un mundo que no refleja necesariamente la realidad que vivimos. 
La ortodoxa neoliberal al asumir el pleno empleo automático, no considera que el desempleo, en sus diversas formas, deba ser un problema a abordar y lo único importante es reducir la inflación. Esta visión de pleno empleo, en el caso peruano, implica desconocer la realidad que vive más del 45 por ciento de la fuerza laboral incorporada en la informalidad y el subempleo.

La elevada cantidad de subempleados que se aprecia en el país exige maneras diferentes de abordarse y resolverse. No se debe olvidar que si bien la inflación reduce el bienestar, los efectos colaterales nocivos que tiene el estar desempleado o con un trabajo poco digno, efectos como la baja autoestima, la inseguridad, la incapacidad de generar el ahorro suficiente para salir de la trampa de vivir siempre a nivel de subsistencia, entre otras cosas, afecta significativamente el bienestar de las personas, posiblemente más allá de lo que lo hace la inflación.

Los enfoques tradicionales que se orientan a corregir los posibles desajustes en el mercado de trabajo mediante soluciones vía la oferta agregada, o los subsidios, o la formalización mediante presión, no parecerían ser las respuestas adecuadas. Creemos que hay que volver a Keynes y estimular la demanda agregada a través, por ejemplo, del gasto discrecional del gobierno actuando como "empleador de último recurso" para reducir o eliminar el subempleo. Hay que tener cuidado con las políticas deflacionarias para controlar la inflación pues al reducir el empleo afectan directamente el bienestar en un grado que puede ser mayor al mal que tratan de corregir.

Lo expuesto no significa que debamos olvidar el peligro obvio que representa la inflación, pero no es lo único que debe corregirse para incrementar el bienestar. Es tanto o más importante dar un trabajo y remuneración dignos. Ambos problemas, el desempleo y la inflación, deben tratarse con la misma intensidad. En la presentación expuesta líneas arriba aumentar los salarios aumentaría el empleo sin necesariamente generar presiones inflacionarias significativas. ${ }^{23}$ Mayores ingresos en manos de los trabajadores evidentemente estimularían la demanda efectiva e impulsarían la producción sin presionar desmedidamente sobre los precios.

Pero, si tuviera que pagarse la generación de empleo con alzas en los precios, el efecto final sobre el bienestar general podría ser positivo. Hay 
estudios empíricos que demuestran que aumentar el empleo mejora más el bienestar que controlar la inflación.

Un interesante análisis econométrico en esta dirección, es el desarrollado por David G. Blanchflower("Is Un employment More Costly Than Inflation?" NBER Working Paper Series. Working Paper 13505. Octubre de 2007). El citado autor menciona que existe un significativo número de trabajos, como los de Rafael Di Tella, Robert J. MacCulloch y Andrew J. Oswald (Marzo de 2001) y Justin Wolfers (Abril de 2003), que han encontrado que tanto el desempleo como la inflación reducen la felicidad. La investigación de Blanchflower extiendelo considerado en la literatura previa, pues analiza más países sobre un periodo de tiempo más amplio. Considera datos agregados para un grupo de25 países comprendiendo a países de la Unión Europea, a cuatro países de Europa del Este además de USA, México, Canadá y Japón, incluyendo micro data para veinte países europeos, con cerca de setecientos mil encuestados. La información tabulada para evaluar, en particular, el impacto de la inflación y el desempleo sobre la felicidad las incluye en las Tablas 7 y 8 (op. cit, pp. 11 y 12).

Blanchflower concluye que si bien tanto tasas altas de desempleo, como tasas mayores de inflación reducen la felicidad de las personas, en la literatura consultada por él, ha encontrado que un incremento de un punto porcentual en el desempleo tiene un mayor impacto sobre la felicidad que un incremento similar en la inflación (op.cit., p. 8, traducción propia). Su misma investigación lo lleva a enfatizar lo siguiente (Blanchflower, op. cit., Resumen y p. 16, traducción propia):“Yo he encontrado que el desempleo deprime el bienestar más que la inflación .... El desempleo es más costoso que la inflación en términos de su impacto sobre el bienestar".

Es que a diferencia de la inflación, el desempleo tiene consecuencias adicionales sobre las personas que afectan el bienestar: si el desempleo (y el empleo informal) es alto, ello aumenta el temor a perder el puesto de trabajo y si este desempleo aumenta, dicho temor aumentará, lo que agrega un costo extra a la pérdida de bienestar. A ello debe agregarse el costo social de la desesperación ante ingresos muy bajos o nulos (si se pierde el trabajo y no se puede encontrar otro), o el costo social de dedicarse al delito si no hay alternativas de trabajo. 


\section{Conclusión}

Se debe insistir en que es el momento de dedicarle más atención a reducir el desempleo disfrazado de informalidad, con acciones directas del gobierno diseñadas específicamente con este propósito. Ello mejoraría el bienestar de un número significativo no solo de los peruanos sino de muchos países que experimentan problemas similares, al permitirles a sus trabajadores un nivel de vida mas digno y disminuyéndoles el temor a perder aun lo poco que perciben.

Una de estas acciones es la sugerida aquí inspirada en lo enfoque Poskeynesiano, que cambia significativamente la manera como se analiza el mercado de trabajo, ofreciendo un enfoque diferente y posiblemente más realista. Un enfoque que aboga, al menos como primera aproximación, por la acción directa del estado en la reducción del desempleo y subempleo sin pagar con inflación. ${ }^{24}$ Como se ha apreciado, la baja en los salarios propuesta por la ortodoxia Neoclásica como una forma de reducir el desempleo no sería adecuada. Por otro lado, las políticas de reducción de demanda necesariamente recesivas que se han aplicado para contener la inflación tienen un costo anti-empleo que reduce el bienestar.

Es evidente que lo sugerido aquí no es lo definitivo; de hecho, existen otras alternativas para abordar los problemas descritos. No obstante, lo que se ha querido enfatizar es que debe ser preocupación prioritaria y directa del gobierno alcanzar el pleno empleo con salarios dignos y no confiar el logro de este objetivo al libre accionar de las fuerzas del mercado. Es importante recordar que si bien el bienestar aumenta tanto si se reduce la inflación como el desempleo, reducir la desocupación en todas sus formas es socialmente más rentable que controlar la inflación.

Una sugerencia final es que se deben revisar las políticas recesivas basadas en teorías que no parecen actuar en la dirección de mejorar los niveles de empleo. Es importante enfatizar que combatir la inflación no es malo, lo que es malo es que las políticas antiinflacionarias generen desempleo abierto y disfrazado, con una pérdida neta en el bienestar de los ciudadanos.

Es sumamente sugerente finalizar citando a Seccareccia, al que se ha seguido de cerca en esta presentación(op. cit. “Observaciones Finales”, p. 38. Traducción propia): 
Después de más de un cuarto de siglo de haberse ofrecido solamente dosis más y más grandes de austeridad con el fin de combatir una inflación anticipada que no existe, resulta verdaderamente refrescante que allá afuera hayan economistas que han tenido el coraje de sacar al frente nuevamente el objetivo del pleno empleo. La cuestión entre aquellos de nosotros que están fuertemente comprometidos con el pleno empleo no es lograr este objetivo en sí, que los economistas neoclásicos inflexiblemente rechazan en favor de alguna elusiva NAIRU, sino más bien que tipo de pleno empleo es el que sentimos que es el más deseable para una sociedad libre y preocupada que querría ver erradicado el desempleo involuntario. Para aquellos de nosotros que creemos en una economía socialmente responsable, esta cuestión necesita ser seriamente abordada.

\section{Referencias Bibliográficas}

Blanchflower, David G. (2007). Is Unemployment More Costly Than Inflation? En: NBER Working Paper Series. Working Paper 13505, octubre, p. 1-40.

Cagan, Phillip D. (1956). "TheMonetary Dynamics of Hyperinflation”. In Friedman, Milton (ed.). Studies in theQuantityTheory of Money. Chicago: University of Chicago Press. Pp. 153-182. ISBN 0-226-26406-8.

El País (2006). El Factor Phelps por Joseph P. Stiglitz, España.https://elpais.com/ diario/2006/12/22/opinion/1166742016_850215.html.

Friedman, Milton (1962). Capitalism and Freedom. University of Chicago Press, Nueva Edición 1982 (Fortieth anniversary edition): Chicago, USA, 202p.

Friedman, Milton (1968). "The Role of MonetaryPolicy," American EconomicReview 58, May, pp. 1-17.

Johnson, Harry G. (1971). The Keynesian Revolution and the Monetarist Counterrevolution. En: American Economic Review. Vol. 61, $\mathrm{N}^{\circ}$ 2, Papers and Proceedings of the Eight Thirdy Annual Meeting of American Economic Association, mayo, p. 1-14.

Keynes, John M. (1965). Teoría General sobre la Ocupación, el Interés y el Dinero. Traducción de Eduardo Hornedo. Revisión de Angel Martín Pérez. Fondo de Cultura Económica. Séptima Edición en Español: México, 339p.

Lavoie, Marc (2000). Un Análisis Comparativo de la Teoría Poskeynesiana del Empleo. En: Investigación Económica, Vol. LX, № 232, abril-junio, p. 15-65.

Phelps, Edmund S. (1967). "PCs, Expectations of Inflation, and OptimalUnemploymentOver Time," Economica 34, August, pp. 254-81. 
Phillips, Arthur W. (1958). The Relation Between Unemployment and the Rate of Change of Money Wages in the United Kingdom: 1861-1957. En: Economica. New Series. Vol. 25, № 100, november, p. 283-299.

Samuelson, Paul A. y Solow, Robert Solow, (1960). Analytical Aspects of AntiInflation Policy. En: American Economic Review 50, p. 177-194.

Seccareccia, Mario (2004). "What Type Of Full Employment? A Critical Evaluation of "Government as the Employer of Last Resort" Policy Proposal. En: Investigación Económica, Vol. LXIII, N²47, enero-marzo, p. 25-43.

Segura, Jorge (2014). La Aparición de los Nuevos Clásicos y Neo-Keynesianos. En: Estratega Financiero. https://estrategafinanciero.com/la-aparicion-de-losnuevos-clasicos-y-neo-keynesianos/) p. 1-25.

\section{NOTAS}

1. Este tipo de planteamiento es parecido a la función de un banco central actuando como prestamista de último recurso.

2. Es conocido que Keynes definía como "Clásicos" a todos los economistas que no coincidían con su forma de analizar los hechos económicos.

3. Porque se experimenta lo que Keynes denominara "Incertidumbre Fundamental".

4. La política del New Deal aplicada por Franklin D. Roosevelt en los EE.UU: es un ejemplo destacable.

5. Esta posición fue planteada por Eugene Fama (premio Nóbel de economía el 2013). Ya en 1970 sostenía que un mercado eficiente es aquel en el que los precios expresan toda la información existente.

6. "The Keynesian Revolution and the Monetarist Counter-revolution." American Economic Review. Vol. 61, $N^{\circ}$ 2, Papers and Proceedings of the Eight Thirdy Annual Meeting of American Economic Association, mayo de 1971.

7. Ello dio origen a lo que se conoce como la "Contrarrevolución Neoclásica": la Escuela Monetarista partidaria de la libre operación de los mercados sin mayores restricciones, aunque dentro de un régimen monetario estrictamente establecido por la autoridad monetaria.

8. Paul Samuelson siempre se consideró "el auténtico Keynesiano". Su tesis doctoral "Fundamentos del Análisis Económico" (1947) es una interpretación, bastante elaborada, de la visión de Keynes sobre la economía.

9. Esta sería la "Segunda Gran Síntesis", después de la Síntesis de Alfred Marshall, que juntara la Teoría Clásica Ricardiana con la Escuela Marginalista.

10. Aunque es importante señalar que esta aceptación no fue universal. De hecho, Joan Robinson se refirió a ella como la propuesta que "mandó a dormir a Keynes".

11. Arthur Phillips, estableció la relación entre el cambio en los salarlos y la tasa de desempleo de la mano de obra en su trabajo "The Relation Between Unemployment and theRate of Change of Money Wages in theUnitedKingdom: 1861-1957"; A. W. Phillips. Economica. New Series. Vol. 25, № 100 (Nov., 1958), (pp.283-299),que se generalizara más tarde para expresar la vinculación de 


\section{Pensamiento Crítico Vol. 23. $\mathrm{N}^{\circ} 2$}

la tasa de variación en el nivel general de los precios con la tasa de desempleo Con ello se concluye que es posible, en un enfoque típicamente Keynesiano, considerar la inflación y el desempleo en un mismo esquema de análisis.

12. De una relación entre el cambio en los salarios y la tasa de desempleo, es posible arribar a la relación entre la tasa de inflación y la de desempleo. Asumiendo que los empresarios tienen la capacidad de fijar los precios y lo hacen siguiendo la regla del "Mark-up" (El Mark Up es el monto que el productor agrega, como utilidad, al precio de costo por unidad del producto para fijar su precio de venta. Este monto puede ser una cantidad fija calculada como un porcentaje del costo de producción).

13. La relación inversa entre la tasa de desempleo y la de inflación fue formulada inicialmente por Irving Fisher a fines del Siglo XIX. Le daba al gobierno la posibilidad de lograr un consenso entre el desempleo y la inflación que satisfaga a los agentes económicos, ya que resultaba imposible lograr simultáneamente la reducción de ambas tasas.

14. Generalmente se considera a $\left(u^{*}\right)$ como la NAIRU, la tasa de desempleo que no acelera la inflación; esto es, aquella que mantiene la inflación estable.

15. El hecho que la información necesaria para formular estas expectativas se base en los datos económicos disponibles en el pasado y en el presente, harían a tales expectativas "deterministas" o "ergódicas".

16. Es importante citar lo que Joseph E. Stiglitz escribió en relación con el desempleo y la NAIRU". (Diario "EL País" de España. "El Factor Phelps". Joseph P. Stiglitz. 22 de dic. de 2006). Fuente: https:// elpais.com/diario/2006/12/22/opinion/1166742016_850215.html:

La tasa de paro (desempleo) de inflación estable no es inmutable; de modo que los gobiernos pueden poner en práctica políticas estructurales, de manera que la economía podrá operar con niveles de desempleo más bajos, a diferencia de las políticas que se centran exclusivamente en la inflación, dado que (como señala Phelps) la relación entre paro e inflación es altamente inestable". Por ello, "concluir que no se puede hacer nada contra el desempleo o que las autoridades monetarias deben centrarse exclusivamente en la inflación, significa utilizar de un modo distorsionado los análisis de Phelps sobre la llamada 'tasa de paro de inflación estable (NAIRU). La obra de Phelps ayuda a comprender la complejidad de las relaciones entre la inflación y el desempleo y el importante papel que juegan las expectativas en esa relación".

17. La inversión es aquí exógena, dependiendo solo de los "animal spirits".

18. En línea con los planteamientos de J.S. Mill y M. Kalecki.

19. Igualando la oferta agregada (OA) con la demanda agregada (DA), se obtiene:

$$
\begin{aligned}
& P\left(N-N_{k}\right) \alpha=w_{v} N_{v}+w_{k} N_{k}+\beta P ; \text { donde } w_{k}=\varphi w_{v} \text {, luego: } \\
& P\left(N-N_{k}\right) \alpha-\beta P=w_{v} N_{v}+\varphi w_{v} N_{k} \\
& P\left[\left(N-N_{k}\right) \alpha-\beta\right]=w_{v}\left(N_{v}+\varphi N_{k}\right) \\
& P\left[\left(N-N_{k}\right) \alpha-\beta\right]=w_{v}\left[\left(N-N_{k}\right)+\varphi N_{k}\right] \\
& P\left[\left(N-N_{k}\right) \alpha-\beta\right]=w_{v}\left[N-N_{k}(1-\varphi)\right] \\
& P\left[\left(N-N_{k}\right) \alpha-\beta\right]=w_{v}\left[N+N_{k}(\varphi-1)\right] ; \text { entonces: } \\
& w_{v} / P=\left[\left(N-N_{k}\right) \alpha-\beta\right] /\left[N+N_{k}(\varphi-1)\right]
\end{aligned}
$$

20. Una deducción de la función de demanda por mano de obra con similares características; esto es, que establece una relación positiva entre la cantidad demandada de trabajo y los salarios reales, 
puede encontrarse también en Edward J. Nell(“Wages, Inflation and the Labor Market," 1988. cap. 25, pp.: 565-566).

21. Es importante recordar la manera como Keynes analiza esta situación. Para él dicho "bolsón" representaría una situación de "desempleo abierto" generada porque la demanda agregada es insuficiente; de manera que al incrementarla se eliminaría esta brecha.

22. Wray, como se citó arriba, ha analizado en diferentes artículos la intervención del gobierno en el logro del pleno empleo con estabilidad de precios, entre los que destacan los citados por Seccareccia (op. cit.).

23. Consideramos interesante incluir el siguiente comentario(J. Stiglitz, art. periodístico citado):

En los primeros años del decenio de 1990, la Reserva Federal y otros bancos centrales, pensaban que la tasa de paro de inflación estable estaba en torno al 6\%-6,2\%. Basándonos en ciertos cambios en la economía, yo y el equipo que trabajaba conmigo en el gabinete económico asesor del presidente Clinton opinábamos que era mucho menor. Teníamos razón. La tasa de desempleo bajó a un 3,8\% sin que la inflación se disparara.

24. Como muchos Poskeynesianos han comentado, Keynes nunca habría aceptado "cambiar mocos por babas". Jamás habría planteado que la solución de un problema económico (la inflación) tendría que ocurrir a costa de generar otro (desempleo). 